\title{
Managing mixed fisheries for bio-economic viability
}

\author{
S. Gourguet ${ }^{a, b, c, *}$, C. Macher ${ }^{b}$, L. Doyen ${ }^{a}$, O. Thébaud ${ }^{b, c}$, M. Bertignac ${ }^{d}$, O. Guyader $^{b}$
}

\begin{abstract}
${ }^{\text {a }}$ CNRS-MNHN, CERSP UMR 7204, CP 51, 55 rue Buffon, 75005 Paris, France
b IFREMER, UMR AMURE, Département d'Economie Maritime, BP 70, 29280 Plouzané, France

${ }^{c}$ CSIRO, Marine and Atmospheric Research, Ecoscience Precinct, 41 Boggo Road, Dutton Park, QLD 4102, Australia

d IFREMER, Département Sciences et Technologies Halieutiques, Laboratoire de Biologie des Pêcheries, BP 70, 29280 Plouzané, France
\end{abstract}

*: Corresponding author : Sophie Gourguet, email addresses : sophie.gourguet@gmail.com ; sophie.gourguet@csiro.au

\begin{abstract}
:
Management of fisheries for sustainability requires dealing with multiple and often conflicting objectives. A stochastic viability approach is proposed to address the trade-offs associated with balancing ecological, economic and social objectives in regulating mixed fisheries, taking into account the complexity and uncertainty of the dynamic interactions which characterize such fisheries. We focus on the demersal fishery in the Bay of Biscay and more specifically on the fleets harvesting Norway Lobster (Nephrops norvegicus), Hake (Merluccius merluccius) and Sole (Solea solea). A bio-economic multi-species and multi-fleet model with technical interactions is developed to examine the trade-offs between preserving Spawning Stock Biomass (SSB) of every species and maintaining the economic profitability of the various fishing fleets. Different management strategies are tested and compared. Results suggest that ensuring viability of this demersal fishery requires a significant decrease in fishing capacity as compared to the reference year. The simulations allow comparing the trade-offs associated with different allocations of this decrease across fleets.
\end{abstract}

Keywords: Bay of Biscay ; Bio-economic model ; Co-viability ; Fisheries ; Uncertainty 


\section{Introduction}

Marine biodiversity is under extreme pressure worldwide as a result of overexploitation, pollution and habitat loss (Ye et al., 2012). Overcapacity and overfished populations, as well as the indirect effects of fisheries on marine ecosystems, reflect the difficulties faced by management in achieving the principal goal of sustainability. One of the reasons put forward to explain the limited success of fisheries management is their frequent focus on single targeted species, rather than on the entire set of species affected by fishing. Because such approaches ignore multi-species and multi-fleet interactions, their effectiveness is limited where such interactions are an important driver of fishing mortality and of economic profitability, particularly in mixed fisheries. Moreover, understanding the trade-offs between ecological, economic and social objectives is important in designing policies to manage ecosystems and fisheries (Cheung and Sumaila, 2008). As stressed by Pikitch et al. (2004), Kempf (2010), there is nowadays widespread acceptance that a more integrated perspective is needed, if these multiple objectives are to be successfully addressed in designing fisheries management regulations for sustainable use of marine living resources.. However, the way to operationalize integrated approaches to the management of mixed fisheries remains controversial as pointed out in Sanchirico et al. (2008), Doyen et al. (2012). Single-species targets and reference points may still be appropriate, but need to be adapted (Pikitch et al., 2004, Hall and Mainprize, 2004). Bio-economic models have been proposed as a means to explore these issues, taking into account socio-economic dimensions, and the complexity of feedback effects between anthropogenic activities and 
natural resources (Prellezo et al., 2012). Growing efforts have been made to develop modelling approaches allowing to assess alternative management options for complex fishery systems. Plagányi (2007) provides an overview of the relative merits and limitations of the different modelling approaches in this domain. Management Strategy Evaluation has been widely recognised as a relevant framework to test the robustness of alternative management procedures to the uncertainties that characterize fishery systems (Punt and Smith, 1999, Kell et al., 2007). Using this framework, several applications have been developed for the northern hake fishery (Murua et al., 2010, Garcia et al., 2011). Viability modelling is also proposed by several authors (Béné et al., 2001, Cury et al., 2005, Eisenack et al., 2006, Bene and Doyen, 2008, Baumgärtner and Quaas, 2009, Doyen et al., 2012) as a relevant bio-economic modelling framework. Viability theory - introduced mathematically by Aubin (1990) - aims at identifying decision rules such that a set of constraints, representing various objectives, is respected at any time. It can be useful in multi-criteria contexts as this approach exhibits a domain of possibilities, feasibility and trade-offs between potentially conflicting objectives or constraints (Baumgärtner and Quaas, 2009). The approach is also closely related to the maximin, or Rawlsian, approach with respect to intergenerational equity (Martinet and Doyen, 2007, Doyen and Martinet, 2012) as constraints can be assumed to apply throughout both present and future time periods. Furthermore, stochastic viability (Doyen and De Lara, 2010) can handle issues of bio-economic vulnerability, risks, safety and precaution by compiling ecological and economic goals in a random context and expanding the Population Viability Analysis (PVA) used in conservation biology to address extinction risks for populations. The viability approach has been applied to the bio-economic management of renewable resource systems, especially fisheries in Béné 
et al. (2001), Eisenack et al. (2006), only a few of which are dedicated to case studies with real data (Mullon et al., 2004, Martinet et al., 2007, De Lara et al., 2007, Chapel et al., 2008, Doyen et al., 2012).

The objective of the present paper is to use the framework of viability analysis to address the formal modelling of trade-offs between conflicting objectives in the management of a mixed fishery. We apply the framework to the Bay of Biscay demersal mixed fishery. A discrete-time stochastic bio-economic model is developed and calibrated based on the data available on the fishery. The model is used to explore alternative management strategies, with particular emphasis on those which allow joint ecological-economic viability of three main exploited fish species - Norway Lobster (Nephrops norvegicus), Hake (Merluccius merluccius) and Sole (Solea solea) and of the sixteen sub-fleets (trawlers and gill-netters) harvesting these species.

\section{Material and methods}

\subsection{The Bay of Biscay case study}

The Bay of Biscay demersal mixed fishery operates in divisions VIIIa and $b$ of the ICES grid (Figure 1). French, Spanish and Belgian fishery fleets operate in this area. The main gears used in these fisheries are trawl, gill-net and longline, and all induce variable levels of impacts on a wide range of species. Under the European data collection framework for fisheries, a number of fishery-independent surveys, data collection programs,

stock assessments based on virtual population analysis (vpa) models (ICES, 2009) and research projects have been carried out over the years (ICES, 2009, http: //www . ices. dk/datacentre/StdGraphDB . asp, http: //wWw . umr-amure.fr/pg_partenarial_ 


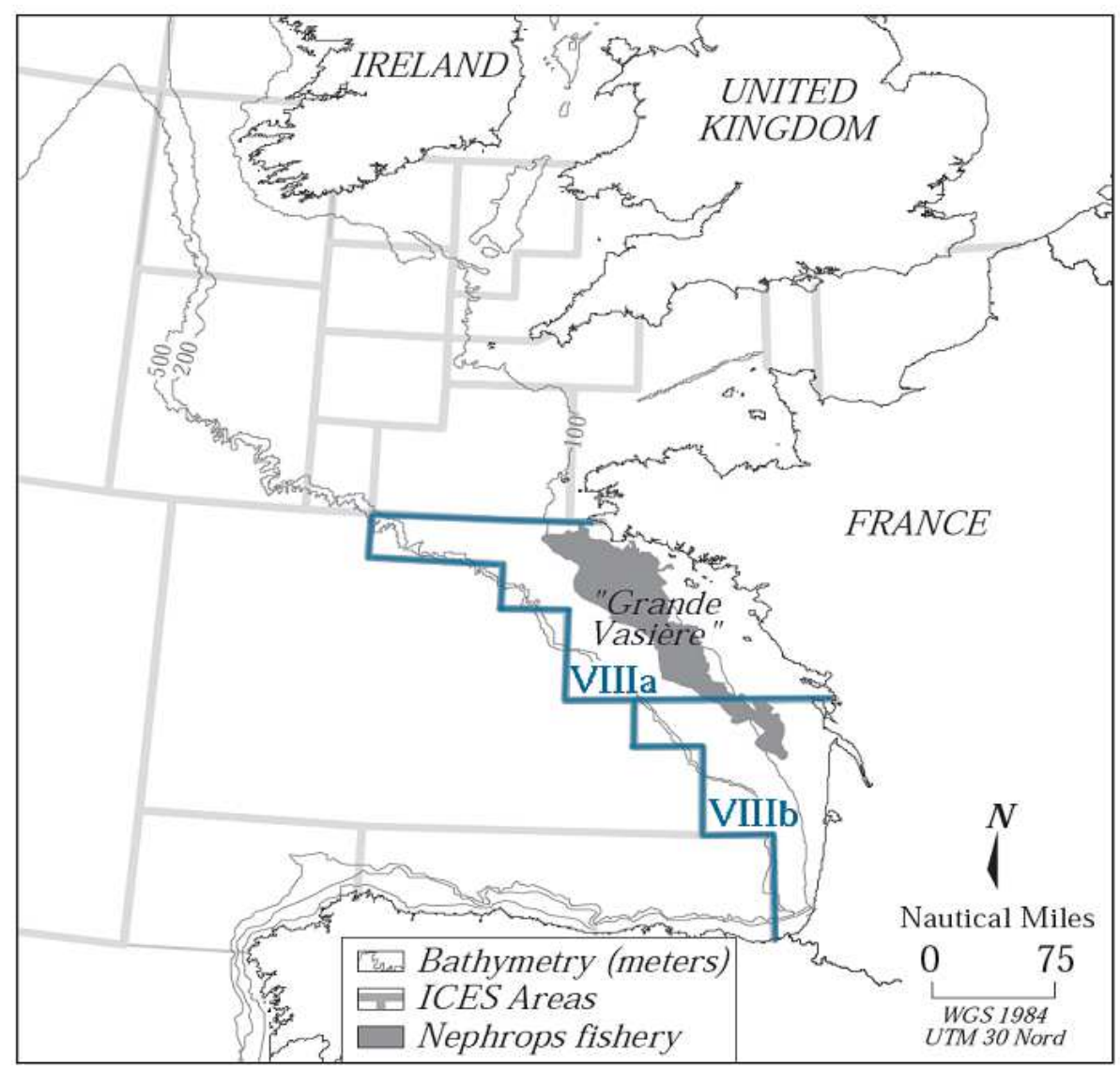

Figure 1: ICES Divisions VIIIa,b Source: Macher et al. (2008)

bioeco.php), which provide both biological and economic information that can be used to calibrate a bio-economic model of the French component of the fishery ${ }^{1}$. According to Daurès et al. (2008) among the 200 species caught in the Bay of Biscay, 20 species correspond to $80 \%$ in volume of the landings in 2007 . Three of the most important species in percentage of the total French national landing value include Nephrops (6\%), Hake (7 $\%)$ and Sole $(11 \%)$. The model we develop aims to represent the dynamics of these three

\footnotetext{
${ }^{1}$ Only French economic data were available for this study.
} 
species.

The French fleets which target these species can be separated in four main groups of vessels based on their main gear used and structure of landings: Nephrops trawlers, various fish trawlers, Sole gill-netters and various fish gill-netters (Macher et al., 2011). These four fleets involved 577 vessels in 2008 and their total turnover amounted to 206 million $€$. The four fleets can be further sub-divided into sixteen sub-fleets according to the length-class of vessels and their associated cost structure. A 17th fleet is also considered in the model to account for the fishing mortalities caused by vessels that do not belong to the sixteen sub-fleets, particularly Spanish and Belgian vessels.

Figures 2 and 3 capture the major interactions in the Bay of Biscay mixed demersal fishery which are taken into account in our analysis. Technical interactions between fleets are illustrated in the figure 2, which shows the estimated number of individual fish caught by each fleet during the year 2008. These numbers include landed but also discarded individuals. Bottom trawls, in particular, are poorly selective gears and their use induces catches of non-targeted fishes (by-catch and by-product) or unwanted length grades of the targeted species. Most of these catches are usually discarded (ICES, 2009). In the Bay of Biscay, Nephrops and Hake are the most discarded species in weight and numbers. While the Nephrops trawlers target mainly Nephrops, they also have an important impact on juvenile Hake (as shown by figure 2) due to the fact that the Nephrops fishing grounds are located on a Hake nursery area. Discarding leads to negative impacts on stock renewal as discards have a high mortality rate (Guéguen and Charuau, 1975, Alverson et al., 1994). However, neither the Nephrops trawlers nor the various fish trawlers depend on Hake for their revenue, as shown in figure 3 which illustrates the contribution of each species to the 
gross income of each fleet. This is characteristic of a technical interaction in which the fishing mode of Nephrops trawlers has an unsought joint impact on Hake resources, which affects mainly other fleets for which this species is an important source of revenue. Many other similar interactions exist between sub-fleets, as illustrated by the figure 3 .

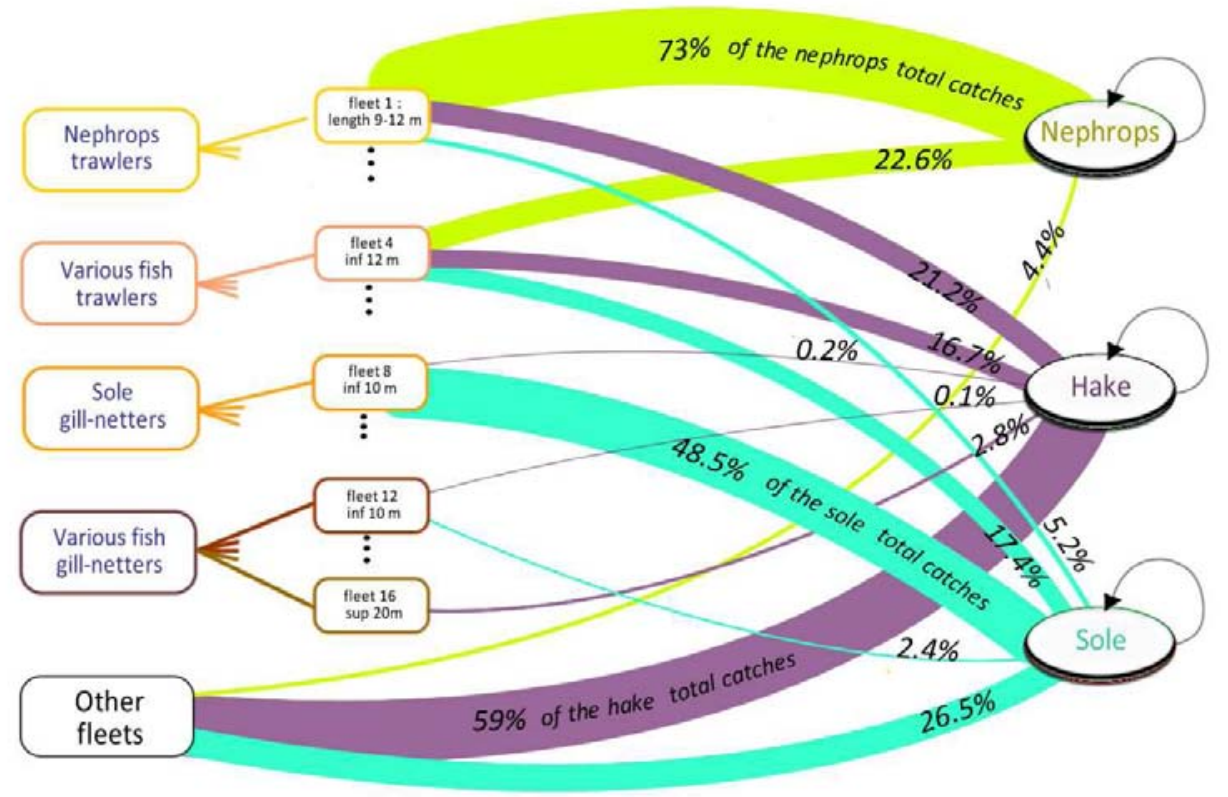

Figure 2: Stylized representation of the Bay of Biscay mixed demersal fishery used as a basis to develop the bio-economic model. The width of the arrows is proportional to the percentage of total number of individual fish caught by the fleets in 2008 , including both landings and discards.

The management of these fisheries mainly relies on conservation measures: a Total Allowable Catch (TAC) revised each year, a minimum landing size (MLS) and a minimum trawl mesh size. Nephrops are targeted by bottom trawlers on a sand-muddy area called "La Grande Vasière" (Figure 1). A major part of the Nephrops landings (in weight) from VIIIa,b are taken by French trawlers. The figure 2 shows that a large amount of Nephrops are caught by the "other fleets" fleet, however most of these individuals are not landed. 


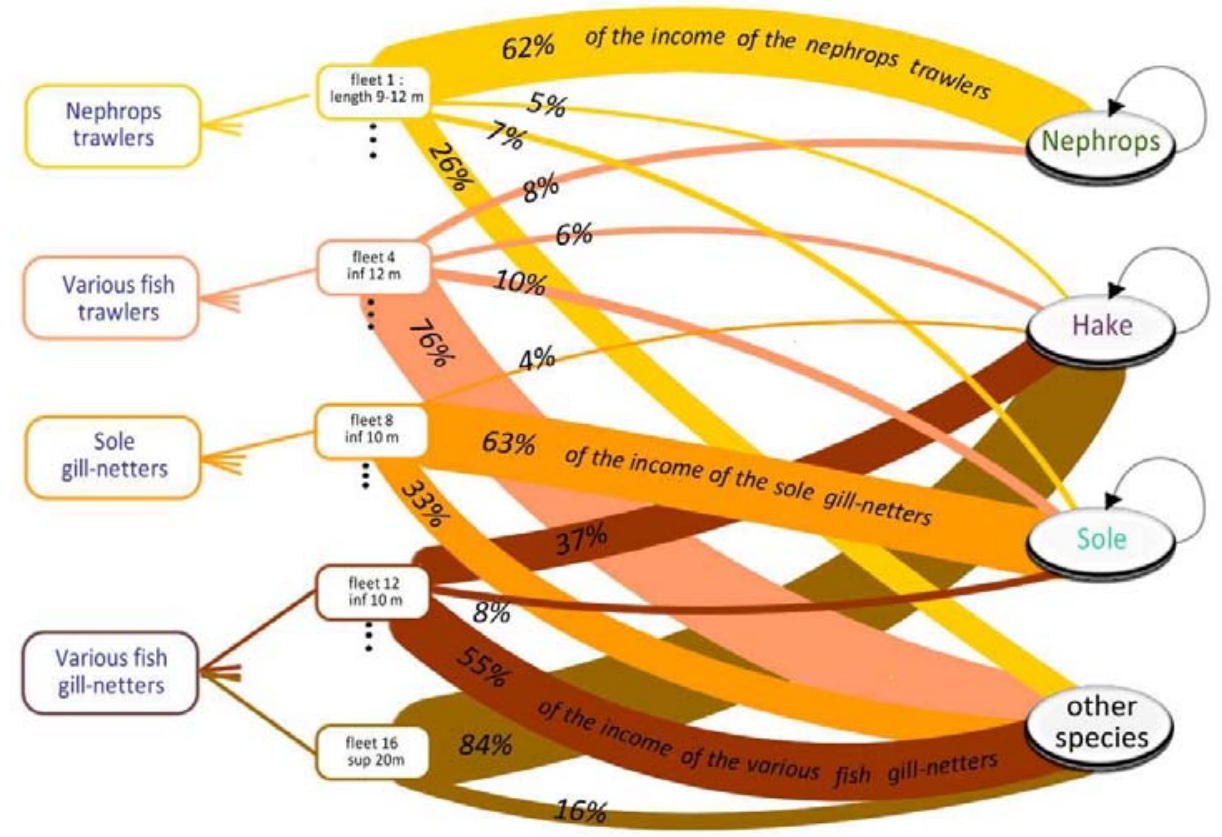

Figure 3: Stylized representation of the contribution of each species to the gross income of each fleet in 2008. The width of the arrows is proportional to the contribution (in percentage) of each species to the total gross income of each fleet.

They correspond for most of them to individuals below the minimum landing size. The Nephrops trawler fleet is one of the most important segments of the French fleet in the Bay of Biscay (ICES, 2010). The fleet indeed represents about one quarter of the French trawlers in this area. With regards to access regulations, a limited entry license system has been enforced since 2005. However, it does not include individual limitations of effort or catches. The high level of catches and discards of younger age groups below the MLS contributes to economic inefficiency of the exploitation (Macher and Boncoeur, 2010). The stock was assessed in 2008 and ICES concluded that its SSB was relatively stable and advised to maintain current landings. The agreed TAC for 2008 was $4320 t$. The important hake by-catch previously mentioned mainly affects the fleets that depend strongly on Hake, 
which include French gill-netters (accounting for around 30\% of total landings) as well as Spanish fleets (accounting for around 53\% of total landings in 2008) (Macher et al., 2011). The Hake TAC in 2008 was set at 54,000 tonnes, including 20,196 tonnes for the Bay of Biscay area. The Bay of Biscay Sole fishery has two main components: a French gill-net fishery directed at Sole and a French and Belgian trawl fishery. The French fleet is the most important participant in the fishery with landings being close to $90 \%$ of the total international landings, over the available historical series since 1979. The Sole landings in the Bay of Biscay are subject to a TAC regulation in combination with technical measures. The 2008 TAC was set at 4582 tonnes.

\subsection{The bio-economic model}

The bio-economic model we develop captures the main features of the technical interactions which exist between the various components of the Bay of Biscay demersal fishery as described in the previous section. Due to data availability constraints, the focus of the analysis is on the bio-economic outcomes of alternative management strategies for the French fleets. However, the model also captures the influence of foreign fleets on the dynamics of the system, and on the potential outcomes of alternative management strategies targeted at the French fleets. The model relies on the mathematics of controlled dynamic systems (Clark, 1976) and more specifically of discrete time systems (De Lara and Doyen, 2008). It extends the bio-economic model presented in Doyen et al. (2012) in which only Hake and Nephrops were taken into account, and only two aggregated fishing fleets were explicitly represented. Based on the existing understanding of trophic structures in the Bay of Biscay demersal ecosystem Le Loc'h and Hily (2005), no trophic interactions are assumed between these species. 


\subsubsection{A multi-species, multi-fleets, age-structured dynamic framework}

Fish population dynamics are modelled using an age-structured population model derived from the standard fish stock assessment approach (Quinn and Deriso, 1999). Population dynamics are described on a yearly basis and integrate uncertainties regarding recruitment. The age-structured dynamics of the three species are governed by :

$$
\left\{\begin{aligned}
\mathrm{N}_{s, a}(t+1)= & \mathrm{N}_{s, a-1}(t) \exp \left(-M_{s, a-1}-F_{s, a-1}\right), \quad \mathrm{a}=2, \ldots, A_{s}-1 \\
\mathrm{~N}_{s, A_{s}}(t+1)= & \mathrm{N}_{s, A_{s}-1}(t) \exp \left(-M_{s, A_{s}-1}-F_{s, A_{s}-1}\right) \\
& +\mathrm{N}_{s, A_{s}}(t) \exp \left(-M_{s, A_{s}}-F_{s, A_{s}}\right) .
\end{aligned}\right.
$$

where $\mathrm{N}_{s, a}(t)$ stands for the abundance of the exploited species $s=1,2,3$ (Nephrops, Hake and Sole, respectively) at age $a=1, \ldots, A_{s}$. Thus the state $\mathrm{N}_{s, a}(t+1)$ of the stock at time $t+1$ evolves according to both natural $M_{s, a}$ and total fishing $F_{s, a}$ mortality rates of the species $s$ at age $a$. Total fishing mortality of species $s$ at age $a F_{s, a}$ is derived from the sum

of fishing mortality from all 17 sub-fleets in year $t_{0}, F_{s, a, f}\left(t_{0}\right)$ and from the fishing effort multipliers $u$ as described in equation (2):

$$
F_{s, a}=\sum_{f=1}^{17} u_{f} F_{s, a, f}\left(t_{0}\right) .
$$

with $u_{f}$ that stands for the fishing effort multiplier of the sub-fleet $f$. Effort multipliers are defined as the ratio of sub-fleet fishing effort as compared to fishing effort in a reference year, and are introduced as control variables to define management strategies. In this study, effort multipliers are applied to the number of vessels per sub-fleet. The reference year is set at $t_{0}=2008$. Fishing mortalities depend both on the fishing effort by vessel (number 
of days at sea) and the number of vessel by sub-fleet (see the equation (7)). The biological parameters are described in the appendix in tables A.1, A.2 and A.3 for Nephrops, Hake and Sole respectively. The estimated values of $F_{s, a, f}\left(t_{0}\right)$, the fishing mortality of the species $s$ at age $a$ induced by the sub-fleet $f$ in 2008, include both landed and discarded fish, and are detailed in the appendix tables A.4, A.5 and A.6 for Nephrops, Hake and Sole. The parameter values are derived from the ICES databases ${ }^{2}$, reports of the Working Group on the Assessment of Southern Shelf Stocks of Hake, Monk and Megrim (WGHMM) (ICES, 2009) and the Ifremer, SIH, DPMA databases ${ }^{3}$.

\subsubsection{Introducing stochastic recruitment functions}

Recruitment involves complex biological and environmental processes that vary over time. The recruits $\mathrm{N}_{s, 1}(t+1)$ for each species are therefore assumed to be uncertain functions of the Spawning Stock Biomass at time $t$ :

$$
\mathrm{N}_{s, 1}(t+1)=\varphi_{s}\left(\operatorname{SSB}_{s}(t), \omega_{s}(t)\right)
$$

The Spawning Stock Biomass $\operatorname{SSB}_{s}(t)$ of the species $s$ is given by:

$$
\operatorname{SSB}_{s}(t)=\sum_{a=1}^{A_{s}} \gamma_{s, a} v_{s, a} \mathrm{~N}_{s, a}(t)
$$

\footnotetext{
${ }^{2}$ http: //www . ices.dk/datacentre/StdGraphDB.asp

${ }^{3}$ DPMA stands for Direction des Peches Maritimes et de 1Aquaculture which corresponds to the Directorate for Sea Fisheries and Aquaculture at the French Ministry of Agriculture and Fisheries. SIH stands for Systeme dInformation Halieutique, the fisheries information system monitored by Ifremer, the French Research Institute for the Exploitation of the Sea (http://wwz. ifremer.fr/institut_eng).
} 
with $\left(\gamma_{s, a}\right)_{a=1, \ldots, A_{s}}$ the proportions of mature individuals of species $s$ at age $a$ and $\left(v_{s, a}\right)_{a=1, \ldots, A_{s}}$ the weights of individuals of species $s$ at age $a$. The function $\varphi_{s}$ represents the specific stock-recruitment relationship of each species $s$ while $\omega_{s}(t)$ stands for uncertainties affecting the stock recruitment relationships through different possible scenarios $\Omega$. In the present case-study, following STECF (2008) and the approach adopted by the working group WGHMM, the recruitment relationship of the species is set using an Ockham-Razor function as in O'Brien et al. (2002):

$$
\varphi_{s}\left(\mathrm{SSB}_{s}, \omega_{s}\right)= \begin{cases}\omega_{s} \sim \mathcal{U}_{s} & \text { if } \mathrm{SSB}_{s} \geq B_{s}^{\lim }, \\ \operatorname{SSB}_{s} \frac{\bar{R}_{s}}{B_{s}^{\lim }} & \text { if } \mathrm{SSB}_{s} \leq B_{s}^{\lim } .\end{cases}
$$

Here $\mathcal{U}_{s}$ stands for the uniform distribution relying on $R_{s}^{t}$, the historical time series of recruitment of species $s^{4}$ (ICES, 2009). ICES limit reference biomass $B_{s}^{\lim }$ and the mean historical recruitment $\bar{R}_{s}$ values are specified in table A.7 of the appendix. The three species have different biology and life cycles, therefore we assume that their recruitments are uncorrelated.

\subsubsection{Catches and fishing mortality}

For each period $t$, the exploitation of the three species is described by the catches $C_{s, a, f}(t)$. These catches depend on initial fishing mortalities $F_{s, a, f}\left(t_{0}\right)$, effort multipliers $u_{f}$

\footnotetext{
${ }^{4} R_{s}^{i}$ is the sample $\mathrm{i}$ for the species $s$ and $\mathbb{P}\left(\varphi_{s}=R_{s}^{i}\right)=\frac{1}{I}$ with $I$ the number of possible values. Gaussian and continuous uniform distributions were also tested but did not significantly modify the results. Furthermore this "historical data series" method is used by the scientists of the working group WGHMM of ICES.
} 
and abundances $\mathrm{N}_{s, a}(t)$ through the Baranov catch equation:

$$
C_{s, a, f}(t)=\mathrm{N}_{s, a}(t) u_{f} F_{s, a, f}\left(t_{0}\right) \frac{1-\exp \left(-M_{s, a}-\sum_{f=1}^{N_{f}} u_{f} F_{s, a, f}\left(t_{0}\right)\right)}{M_{s, a}+\sum_{f=1}^{N_{f}} u_{f} F_{s, a, f}\left(t_{0}\right)} .
$$

The initial fishing mortality $F_{s, a, f}\left(t_{0}\right)$ can be expressed as:

$$
F_{s, a, f}\left(t_{0}\right)=q_{s, a, f} e_{f}\left(t_{0}\right) \mathrm{K}_{f}\left(t_{0}\right)
$$

where $e_{f}\left(t_{0}\right)$ is the mean value of fishing effort by vessels of sub-fleet $f$ expressed in number of days at sea and $\mathrm{K}_{f}\left(t_{0}\right)$ is the number of vessels by sub-fleet $f$, both for the baseline year 2008. Their values are given in table A.11 in the appendix. The catchability $q_{s, a, f}$ corresponds to the fishing mortality of species $s$ at age $a$ associated with one unit of fishing effort from a vessel of sub-fleet $f$. Catchabilities are assumed constant over the simulation period.

\subsubsection{Income}

The gross income from catches of each sub-fleet $\operatorname{Inc}_{f}(t)$ is then estimated by introducing the market price of the species along with the estimates of discard rates, such that:

$$
\operatorname{Inc}_{f}(t)=\sum_{s} \sum_{a=1}^{A_{s}} p_{s, a}\left(\widetilde{\omega}_{s}(t)\right) v_{s, a, f} C_{s, a, f}(t)\left(1-d_{s, a, f}\right) .
$$

where $v_{s, a}$ is the mean weight of landed individuals of species $s$ at age $a$ and $d_{s, a, f}$ represents the discard rate of individuals of age $a$ by the sub-fleet $f$. Discard ratios were cal- 
ibrated on the data available from the ICES working group WGHMM. ${ }^{5}$ Price $p_{s, a}\left(\widetilde{\omega}_{s}(t)\right)$ corresponds to the market value (euros by $\mathrm{kg}$ ) of species $s$ at age $a$ for year $t$ under the stochastic scenario $\widetilde{\omega}_{s}(t)$. Uncertainties on annual mean market price by species are introduced through a random mean price by species following a Gaussian law as:

$$
p_{s}\left(\widetilde{\omega}_{s}\right) \leadsto \mathcal{N}\left(\mu_{s}^{P}, \sigma_{s}^{P}\right)
$$

Gaussian laws are calibrated from ex-vessel prices for the three species for the 2000-2009 period, recorded in French harbours (data from Ifremer, SIH, DPMA). Prices by species $p_{s}\left(\widetilde{\omega}_{s}(t)\right)$ are assumed to be independent by species and by year. Market price $p_{s, a}\left(\widetilde{\omega}_{s}(t)\right)$ by age $a$ are computed from the annual price by species $p_{s}\left(\widetilde{\omega}_{s}(t)\right)$ as follows:

$$
p_{s, a}\left(\widetilde{\omega}_{s}(t)\right)=p_{s}\left(\widetilde{\omega}_{s}(t)\right) \Upsilon_{s, a}
$$

with $\Upsilon_{s, a}$, an age price coefficient $\Upsilon_{s, a}$ calibrated from 2008 market prices for the three species and for different market categories (defined in terms of the size/age of fish) (Ifremer/SIH/DPMA). Parameters of the Gaussian law $\left(\mu_{s}^{P}, \sigma_{s}^{P}\right)$ for each species and age price coefficient $\Upsilon_{s, a}$ by species $s$ and age $a$ are displayed in the appendix in tables A.1, A.2 and

\section{A.3.}

\footnotetext{
${ }^{5}$ A difference in discards between the Nephrops trawlers and the various fish trawlers was observed. The Nephrops trawlers appear to have a larger impacts on the first age class of Hake than the other trawlers. As discarding rates for Hake and Sole are not known per sub-fleet, we assume that discarding rates are the same for each sub-fleet, equal to the discarding rate of the whole fleet and assumed to be constant over the simulation period. For the same reason, fishing mortality is allocated between the sub-fleets according to their contribution to total landings (see in the appendix: tables A.4, A.5 and A.6 for the values of fishing mortalities by sub-fleet for Nephrops, Hake and Sole and the tables A.8, A.9 and A.10 for the estimated discards).
} 


\subsubsection{Profits}

The economic viability per sub-fleet is assumed to be determined by their economic profitability, that is the difference between their gross income and their costs. The profit $\pi_{f}$ of a sub-fleet $f$ is estimated as follows:

$\pi_{f}(t)=\left(\operatorname{Inc}_{f}(t)+\alpha_{f} u_{f} \mathrm{~K}_{f}\left(t_{0}\right) e_{f}\left(t_{0}\right)\right)\left(1-\tau_{f}\right)-\left(\mathrm{V}_{f}^{f u e l} p_{f u e l}(t) e_{f}\left(t_{0}\right)+c_{f}^{v a r} e_{f}\left(t_{0}\right)+c_{f}^{f i x}\right) u_{f} \mathrm{~K}_{f}\left(t_{0}\right)$.

Here the parameter $\alpha_{f}$ corresponds to the income per unit of effort of sub-fleet $f$ derived from catches of species not explicitly modelled. Incomes from other species are including in an additive fashion as in Raveau et al. (2012). We assume that biomass and price of other species are constant, and that the impacts of modelled fleets on these species are relatively negligible. Rate $\tau_{f}$ is the landing cost by sub-fleet as a proportion of the gross income ${ }^{6} . \mathrm{V}_{f}^{\text {fuel }}$ corresponds to the volume of fuel (in litres) used by fishing effort unit (i.e. days at sea) for one vessel of sub-fleet $f$ and $p_{f u e l}(t)$ is the fuel price by litre of the year $t$ that can be subjected to projection scenarios. The other variable cost $c_{f}^{v a r}$ of a fishing effort unit by a vessel of sub-fleet $f$ includes oil, supplies, ice, bait, gear and equipment costs while $c_{f}^{f i x}$ corresponds to the annual costs associated with vessel of the sub-fleet $f$, including maintenance, repair, management and crew costs, fishing firms, licenses, insurance premiums and producer organisation charges. Cost parameter values in the model are based on the economic data available for 2008 (Ifremer, SIH, DPMA)

\footnotetext{
${ }^{6} \tau_{f}$ could potentially and theoretically be used as policy instrument through a landing tax. However, $\tau_{f}$ is here considered as a landing cost, a levy ad valorem which is paid for landing services. The differences between these landing costs by sub-fleet, displayed in table A.12, relate to the different locations of landings, and associated costs of landing services.
} 
and are assumed to be constant over the simulation period. As mentioned in section 2.2.1, $u_{f}$ corresponds to the fishing effort multiplier of sub-fleet $f$ and is applied to the number of vessels per sub-fleet ${ }^{7}$. The full set of previous parameters used to estimate profits is displayed in the tables A.11 and A.12 in the appendix.

\subsection{Fuel scenarios}

As regards fuel price, two different scenarios are considered: a base case scenario BC where fuel price $p_{\text {fuel }}(t)$ is assumed to be steady over the simulation period and a most likely scenario ML where fuel price increases over time. Fuel prices under the most likely scenario are based on projections from the International Energy Agency (IEA, 2010, CAS, 2012). Table 1 summarizes both fuel scenarios.

Table 1: Fuel price scenarios (in each row) considered in this study. Source:(IEA, 2010, CAS, 2012).

\begin{tabular}{ll}
\hline Scenarios & Description \\
\hline $\mathrm{BC}$ & Base case scenario: constant fuel prices \\
& $p_{\text {fuel }}(t)=p_{\text {fuel,ref }}=0.50 € / \mathrm{L}$ \\
$\mathrm{ML}$ & Most likely scenario: increase of fuel price \\
& $p_{\text {fuel }}(t)=p_{\text {fuel,ref }}$ for $\mathrm{t}=1$ \\
& $p_{\text {fuel }}(t)=p_{\text {fuel }}(t-1)+0.03$ for $\mathrm{t}=2, \ldots, 7$ \\
& $p_{\text {fuel }}(t)=p_{\text {fuel }}(t-1)+0.0115$ for $\mathrm{t}=8, \ldots, 12$ \\
& $p_{\text {fuel }}(t)=p_{\text {fuel }}(t-1)+0.0135$ for $\mathrm{t}=13, \ldots, 20$ \\
\hline
\end{tabular}

\footnotetext{
${ }^{7}$ It is most likely that in circumstances where a decrease in capacity was required to maintain long-term viability of the fishery, the fleets would first try to modulate their fishing effort (and associated variable costs) before vessels left the fishery. Therefore, we first tried to use fishing effort of the sub-fleets as a control. However, it turns out that economic issues in the fishery arise mainly from the annual, rather than variable, cost component of profits.
} 


\subsection{The co-viability diagnostic}

The viability framework of analysis is used to describe trade-offs associated with alternative management approaches for the fishery. This requires the specification of constraints which capture the different objectives that may be pursued in managing the fishery. Given the stochastic nature of the model (i.e. uncertainties on recruitments and market prices), the performance of management strategies must be assessed in terms of the probability for these constraints to be met by the fishery at any point in time, under alternative scenarios (Doyen and De Lara, 2010). We consider two sets of constraints to define the viability of the fishery: the first set of constraints relates to the population viability of the three species; the second set of constraints relates to the economic viability of each individual sub-fleet. Our set of biological constraints is related to Population Viability Analysis (PVA), well-known in biological conservation sciences (Morris and Doak, 2002). Population Viability Analysis (PVA) is a process of identifying the threats faced by a species and evaluating the likelihood that it will persist into the future. PVA is defined as the requirement that the Spawning Stock Biomass of each individual species is maintained above a threshold value. In this study, the thresholds correspond to $B_{s}^{\mathrm{pa}}$, the biomass of precaution of the species $s$ estimated by the International Council for the Exploration of the Sea. The constraint is specified as:

$$
\operatorname{SSB}_{s}(t) \geq B_{s}^{\mathrm{pa}}, \quad s=1,2,3
$$

The ecological performance of a management strategy, involving a particular vector of effort multipliers by sub-fleet $u$, can be assessed by the population viability probability 
$\mathbb{P}_{\mathrm{PVA}}(u)$, as described by :

$$
\mathbb{P}_{\mathrm{PVA}}(u)=\mathbb{P}\left(\text { constraints (12) are satisfied for } t=t_{0}, \ldots, T\right) \text {. }
$$

We also consider the economic objective of maintaining positive profits for the sub-fleets over time (Economic Viability Analysis, EVA):

$$
\pi_{f}(t)>0, \quad f=1, \ldots, 16 .
$$

The economic viability probability of the fishery related to a vector of effort multipliers $\mathbb{P}_{\mathrm{EVA}}(u)$ is thus expressed by:

$$
\mathbb{P}_{\mathrm{EVA}}(u)=\mathbb{P}\left(\text { constraints (14) are satisfied for } t=t_{0}, \ldots, T\right) \text {. }
$$

In effect, this constraint aims to keep each segment of the fishery active (at positive profit levels), and the related social benefits of maintaining employment in each sub-fleet. Given that the sub-fleets are distributed across different coastal regions of the Bay of Biscay, this also ensures the maintenance of active commercial fishing operations and employment all along the coastline from which the fishery operates. The objective thus defined is in fact akin to a social constraint, as it essentially requires that levels of economic profitability achieved by sub-fleets allow these sub-fleets to continue participating in the fishery. In this sense, it is similar to the participation constraint defined by Péreau et al. (2012) in their bio-economic analysis of the effects of ITQ regulations on fisheries.

Co-Viability Analysis (CVA) of the fishery combines PVA and EVA and seeks to assess 
whether a management strategy allows for both sets of constraints to be observed simultaneously. The ecological and economic viability constraints characterize an acceptable sub-region of the phase space within which the fishery evolves. A particular trajectory followed by the fishery will be called viable if it remains in this region during the prescribed period of time, with a sufficiently high probability. Thus the bio-economic performance of a management strategy entailing a particular vector of effort multipliers $u$ can be evaluated by the probability of co-viability of the fishery under this strategy, as defined by the equation (16) :

$$
\mathbb{P}_{\mathrm{CVA}}(u)=\mathbb{P}\left(\text { constraints }(12) \text { and (14) are satisfied for } t=t_{0}, \ldots, T\right) \text {. }
$$

Of particular interest are the vectors of effort multipliers by sub-fleet $u$ such that the probability of co-viability $\mathbb{P}_{\mathrm{CVA}}$ is high enough :

$$
\mathbb{P}_{\mathrm{CVA}}(u) \geq \beta,
$$

where $\beta$ stands for some confidence rate (typically $90 \%, 95 \%$ or $100 \%$ ).

\subsection{Management strategies}

We compare different management strategies relying on different combinations of effort multipliers $u_{f}$. In particular, we compare approaches which would focus on partial management of the fishery, centred on the bio-economic viability of harvesting a partic-

ular species, with strategies which attempt to manage the mix of species and fleets as a whole. The associated effort multipliers can differ between sub-fleets but it is assumed for sake of simplicity that they remain constant over time. Projections are computed over 
twenty years $(T=2028)$ starting from the initial stock abundances $\mathrm{N}\left(t_{0}\right)$ at year $t_{0}=2008$. The values of initial states are given by tables A.1, A.2 and A.3 in the appendix. For each management strategy, viability probabilities are approximated by the proportion of viable trajectories among 1000 simulated trajectories. Each trajectory corresponds to different recruitment levels $\omega()=.\left(\omega_{1}(),. \omega_{2}(),. \omega_{3}().\right)$ and prices $\widetilde{\omega}()=.\left(\widetilde{\omega}_{1}(),. \widetilde{\omega}_{2}(),. \widetilde{\omega}_{3}().\right)$ for the three species, randomly selected every year according to equations (5) and (9). These $\omega_{i}$ and $\widetilde{\omega}_{i}$ are assumed to be independent and identically distributed.

In the following paragraphs we outline the specifications of each strategy.

The status quo (SQ) strategy simulates continued fishing mortalities at levels observed in the 2008 baseline year:

$$
u_{f}^{\mathrm{sQ}}=1, \quad \forall f=1, \ldots, 16 .
$$

The net present value strategy $u^{\mathrm{NPV}}$ is a conventional economic strategy where a central planner aims at maximizing the expected sum of discounted profits at the scale of the entire fishery. There is no guarantee that the profit of each sub-fleet will be positive due to the absence of constraints on these profits. The net present value is calculated as the aggregated value of discounted profits over all the sub-fleets:

$$
\operatorname{NPV}(u)=\mathbb{E}\left[\sum_{t_{0}}^{T} \frac{1}{(1+\rho)^{t}} \sum_{f=1}^{16} \pi_{f}(t)\right]
$$

where the discount rate is set to $\rho=4 \%^{8}$. The combination of effort multipliers which

\footnotetext{
${ }^{8}$ This value of discount rate is used for the evaluation of public projects in France (Portney and Weyant, 1999, Lebègue, 2005).
} 
define this strategy $u^{\mathrm{NPv}}$, is such that:

$$
\operatorname{NPV}\left(u^{\mathrm{NPV}}\right)=\max _{u} \operatorname{NPV}(u)
$$

The co-viability strategy $u^{\mathrm{cvA}}$ intends to guarantee both the conservation of Spawning Stock Biomass of all three species and the economic viability of all the fishing sub-fleets. A central planner requires that both the ecological and economic constraints defined in (12) and (14) are satisfied. The associated combinations of effort multipliers $u^{\mathrm{cvA}}$ are identified such that they maximize the co-viability probability $\mathbb{P}_{\mathrm{CVA}}(u)$ described in (16):

$$
\mathbb{P}_{\mathrm{CVA}}\left(u^{\mathrm{CVA}}\right)=\max _{u} \mathbb{P}_{\mathrm{CVA}}(u) .
$$

Capital inertia and the related difficulties in reducing excess capacity in fisheries are important issues which often plague fisheries management policies (Nøstbakken et al., 2011). To take this constraint into account, the selection of management strategies is carried out such that the distance between the values of $u_{f}$ and status quo $u_{f}^{\text {so }}$ is minimized, ensuring that the capacity adjustments identified as viable entail the least changes in fleet sizes possible. In other words,

$$
\left|u_{\mathrm{CVA}}-u_{\mathrm{sQ}}\right|=\min \left(\left|u-u_{\mathrm{sQ}}\right|, \mathbb{P}_{\mathrm{CVA}}(u)=\max _{z} \mathbb{P}_{\mathrm{CVA}}(z)\right)
$$

The Sole (SOL) strategy investigates a mono-specific management strategy focused on the viability of the Sole fishery. In this sense it is a less cooperative strategy than cva. The effort multipliers $u^{\mathrm{soL}}$ only account for constraints on the Sole $\operatorname{SSB}_{3}(t)$ and profitability 
goals $\pi_{f}(t)_{f=8, \ldots, 11}$ for the Sole gill-netter sub-fleets $(f=8, \ldots, 11)$ :

$$
\left\{\begin{array}{l}
\mathrm{SSB}_{3}(t) \geq B_{3}^{\mathrm{pa}} \\
\pi_{f}(t)>0 \text { for } f=8, \ldots, 11 \\
u_{f}=1 \text { for } f \neq 8, \ldots, 11 .
\end{array}\right.
$$

The associated effort multipliers $u^{\text {soL }}$ are obtained by maximizing the probability that the Sole viability objectives will be met, as follows:

$$
u^{\mathrm{soL}} \in \underset{u}{\operatorname{Argmax}} \mathbb{P}\left(\text { constraints }(21) \text { are satisfied for } t=t_{0}, \ldots, T\right) .
$$

Again, among the different solutions $u^{\mathrm{soL}}$, the one with minimal capacity change are selected as in (20).

The Nephrops (NEP) strategy investigates a mono-specific management strategy focused on the Nephrops fishery. Similarly to the sol strategy, the effort multipliers $u^{\mathrm{NEP}}$ are selected such that only the constraints related to the stock of Nephrops $\operatorname{SSB}_{1}(t)$ and to profits $\pi_{f}(t)_{f=1,2,3}$ of the Nephrops trawlers $(f=1,2,3)$ are considered:

$$
\left\{\begin{array}{l}
\operatorname{SSB}_{1}(t) \geq B_{s}^{\mathrm{pa}}, \\
\pi_{f}(t)>0 \text { for } f=1,2,3, \\
u_{f}=1 \text { for } f \neq 1,2,3 .
\end{array}\right.
$$

Viable combinations of effort multipliers $u^{\mathrm{NEP}}$ are identified by maximizing the probability 
that these objectives are met, as follows:

$$
u^{\mathrm{NEP}} \in \underset{u}{\operatorname{Argmax}} \mathbb{P}\left(\text { constraints (23) are satisfied for } t=t_{0}, \ldots, T\right) .
$$

Again, as in (20), among the different solutions $u^{\mathrm{NEP}}$, the one with minimal capacity change are chosen.

The numerical implementations and computations of the model have been carried out with the scientific software scILAB $^{9}$ 5.2.2. The nonlinear optimization problems (equations (18), (19), (22) and (24)) were solved numerically using the Scilab routine entitled “optim_ga" which relies on a genetic algorithm ${ }^{10}$.

\section{Results}

Outcomes of the five strategies under both fuel scenarios are compared according to the combinations of effort multipliers which they entail, and to their ecological and economic performances (ecological, economic and co-viability probabilities, as well as net present values).

Figure 4 displays the effort multipliers $u_{f}$ by sub-fleet which met the objectives for

\footnotetext{
${ }^{9}$ scILAB is a freeware http://wWw.scilab.org/ dedicated to engineering and scientific calculus. It is especially well-suited to deal with dynamic systems and control theory.

${ }^{10}$ See http://help.scilab.org/docs/5.3.3/en_US/optim_ga.html for details on "optim_ga". Genetic algorithms (GAs) are a search procedure based on Darwinian "survival of the fittest" theory. GAs were developed to solve optimisation problems based on the mechanics of natural selection and genetics such as inheritance, mutation, selection and crossover. The artificial implementation of the natural selection and reproduction into genetic operations have been shown to optimize design problems (Fleming and Purshouse, 2002). GAs optimize by evolving or generating successive populations from an initial random population of individuals to improved populations. This type of numerical method has already been used for bio-economic purposes, for instance in Mardle and Pascoe (2000) and in Sathianandan and Jayasankar (2009).
} 
each strategy under both fuel scenarios. For some management strategies, multiple viable solutions (i.e. effort multiplier values by fleet) are found, therefore effort multipliers on figure 4 are represented by boxplots where range, median and quartiles are represented. To illustrate the fact that, despite the existence of multiple solutions, all combinations of the viable effort multiplier values identified for these sub-fleets are not possible, two particular sets of viable effort multipliers are shown. Table 2 gives the ecological, economic and co-viability probabilities and net present values associated to the five strategies under both scenarios. The viability probabilities and net present values are calculated using equations (13), (15), (16) and (17), respectively. Table 2 also provides the number of viable combinations of effort multipliers that were obtained by strategy. Figures 5 and 6 synthetize the bio-economic scores and trade-offs. Results are detailed in the following subsections.

Table 2: Range of the ecological and economic viability probabilities $\left(\mathbb{P}_{P V A}, \mathbb{P}_{E V A}\right)$, co-viability probabilities $\left(\mathbb{P}_{C V A}\right)$ and net present value (NPV) of total fishery profits associated to combinations of effort multipliers obtained for each management strategy. Number of different optimal combination are also given.

\begin{tabular}{cccccc} 
Strategies & $\begin{array}{c}\mathbb{P}_{P V A} \\
(\text { in } \%)\end{array}$ & $\begin{array}{c}\mathbb{P}_{E V A} \\
\text { (in } \%)\end{array}$ & $\begin{array}{c}\mathbb{P}_{C V A} \\
\text { (in } \%)\end{array}$ & $\begin{array}{c}\text { NPV } \\
\text { (in millions of } € \text { ) }\end{array}$ & $\begin{array}{c}\text { Nb of different } \\
\text { solutions }\end{array}$ \\
\hline SQBC & 98.5 & 31.1 & 30.5 & 685.1 & 1 \\
SQML & 98.5 & 0 & 0 & 525.8 & 1 \\
\hline NPVBC & 100 & 0 & 0 & 1016.6 & 1 \\
NPVML & 100 & 0 & 0 & 934.3 & 41 \\
\hline CVABC & 100 & $95-96.3$ & $95-96.3$ & $654.4-748.6$ & 53 \\
CVAML & 100 & 94.4 & 94.4 & $396.3-429.6$ & 42 \\
\hline SOLBC & 100 & $31.5-31.7$ & $31.5-31.7$ & $709.4-711.2$ & 83 \\
SOLML & 100 & 0 & 0 & $569.2-571.4$ & 45
\end{tabular}



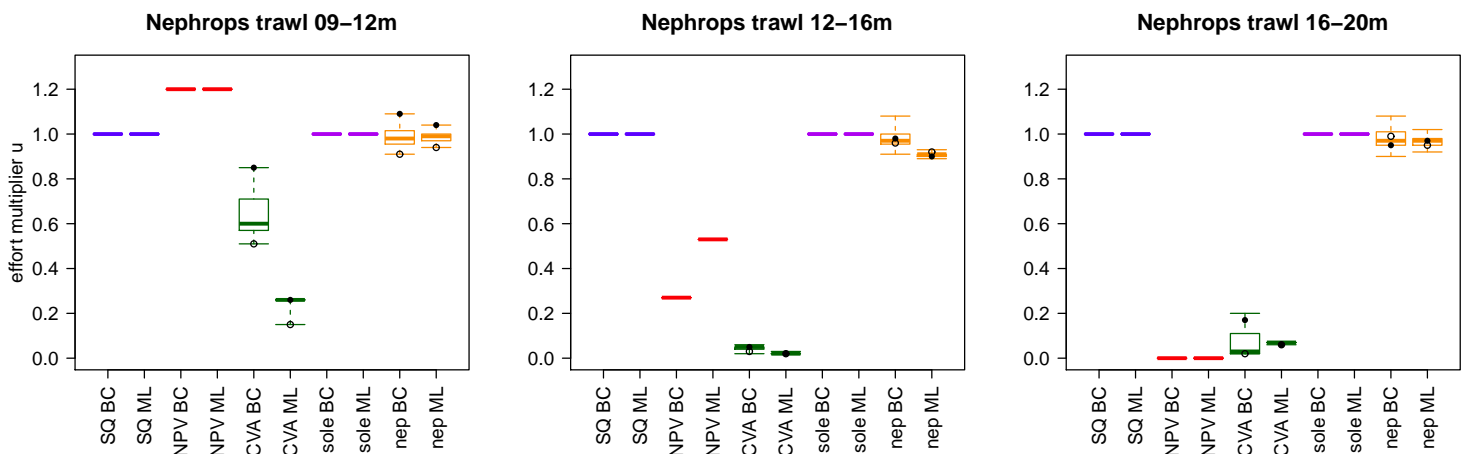

(a) Nephrops trawlers.
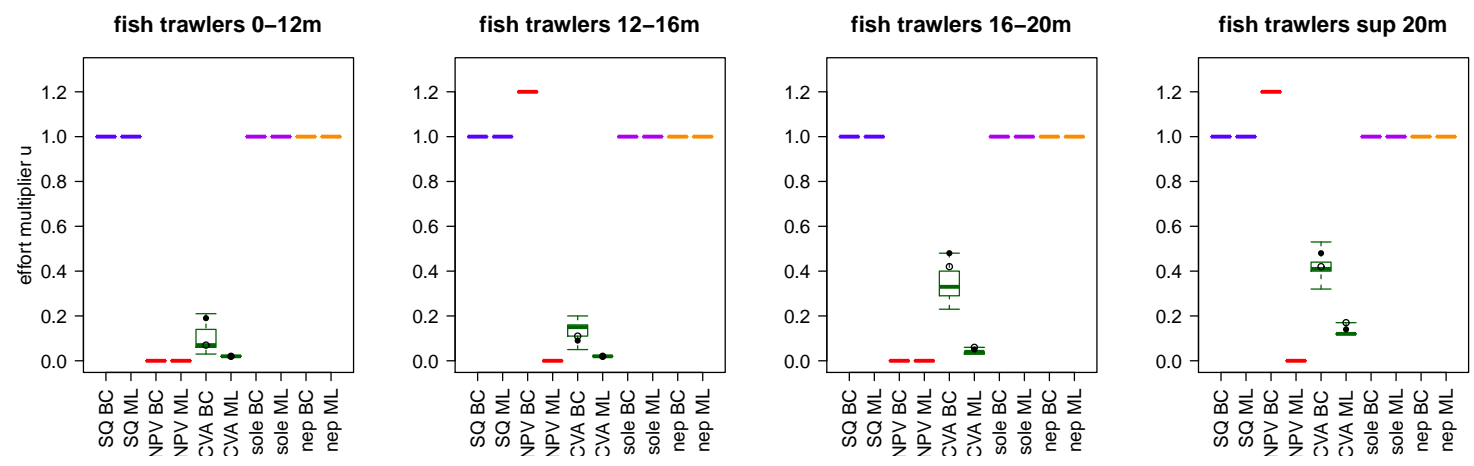

(b) Various fish trawlers.
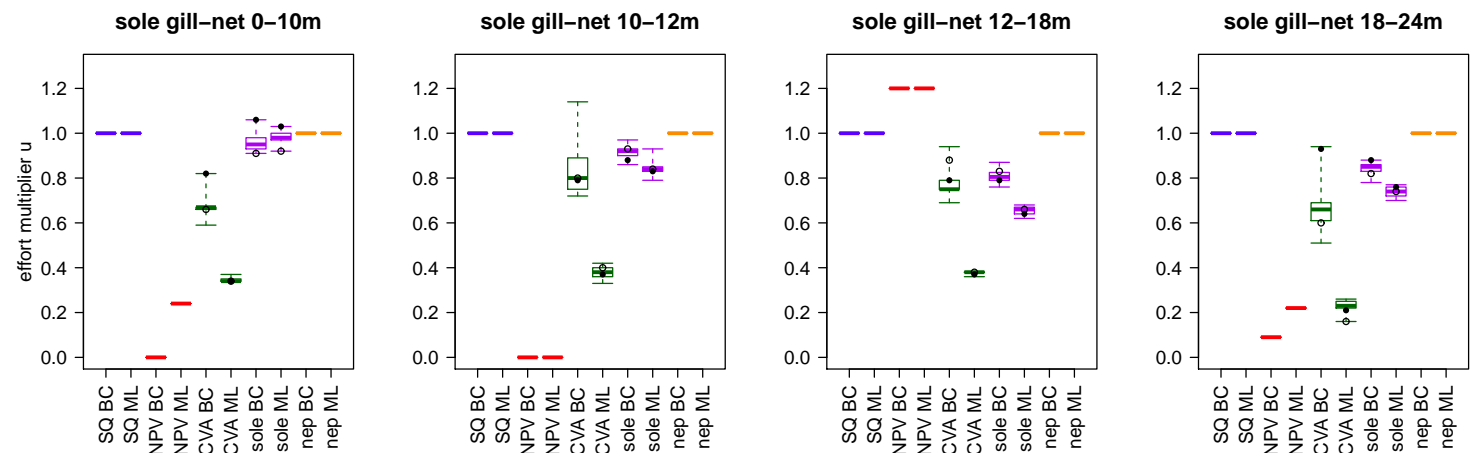

(c) Sole gill-netters.
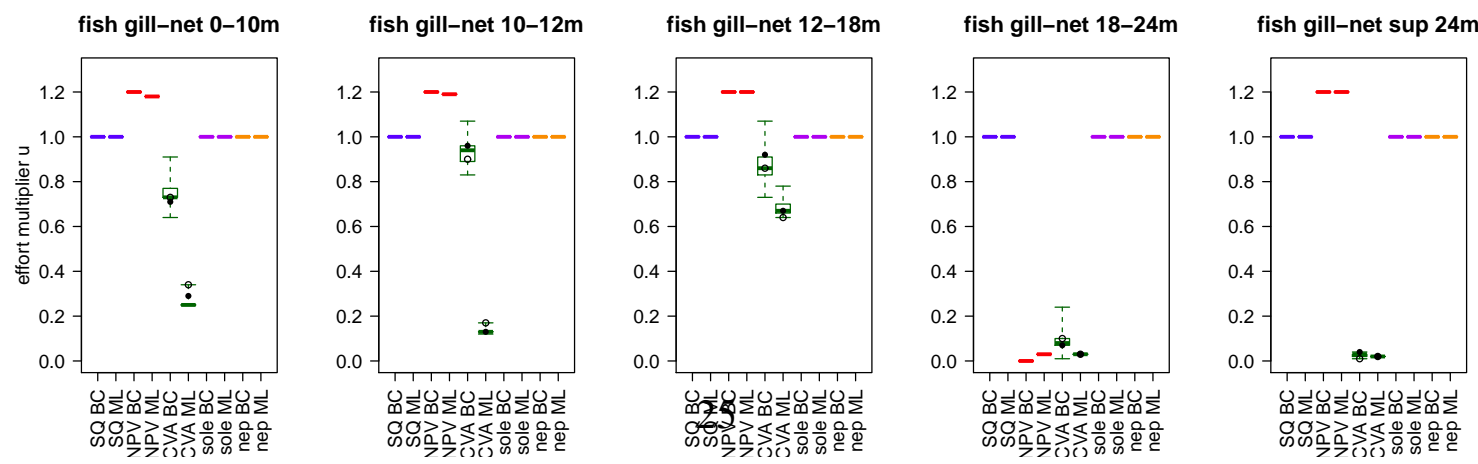

(d) Various fish gill-netters.

Figure 4: Range of the effort multipliers values $u_{f}$ for the different sub-fleets $f$ and the five strategies (SQ, NPV, CVA, SOL and NEP) under both fuel scenarios BC and ML. For the management strategies where different solution are possible (i.e. CVA, sOL and NEP) two different combinations of effort multipliers are displayed. Plain dots stand for one combination and empty dots for another. (a) Nephrops trawlers. (b) Various fish trawlers. (c) Sole gill-netters. (d) Various fish gill-netters. 


\section{EVA vs PVA}

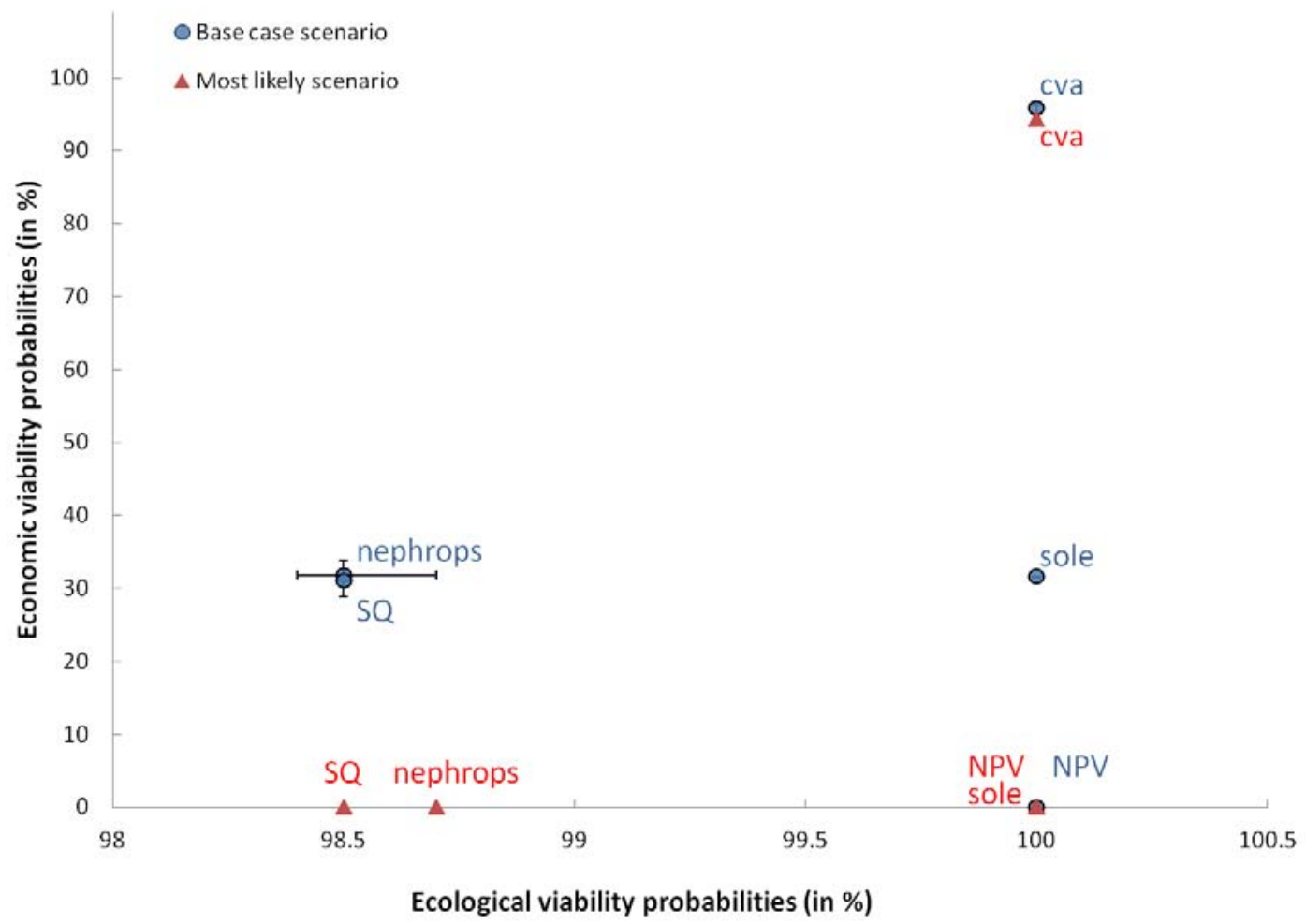

Figure 5: Economic $\mathbb{P}_{\mathrm{EVA}}(u)$ versus ecological $\mathbb{P}_{\mathrm{PVA}}(u)$ performances of each management strategy under both fuel scenarios. The blue dots represent the economic and ecological viabilities of each strategy under the base case scenario and the red triangles under the most likely scenario.

\subsection{Status quo strategy: not economically viable}

Figures 7 to 9 show the projections to 2028, under the status quo strategy, of the $\mathrm{SSB}_{s}(t)$ of each species and the profits $\pi_{f}(t)$ of each sub-fleet under base case and most likely fuel scenarios, respectively. Figure 7 first illustrates that this strategy is almost ecologically viable in the sense that the population viability probability is close to one with $\mathbb{P}_{\mathrm{PVA}}\left(u^{\mathrm{se}}\right)=98.5 \%$. Only some trajectories for the Sole SSB violate the precautionary threshold $B_{3}^{\mathrm{pa}}$. The other species fluctuate in safety zones despite the uncertainties affect- 
NPV vs CVA

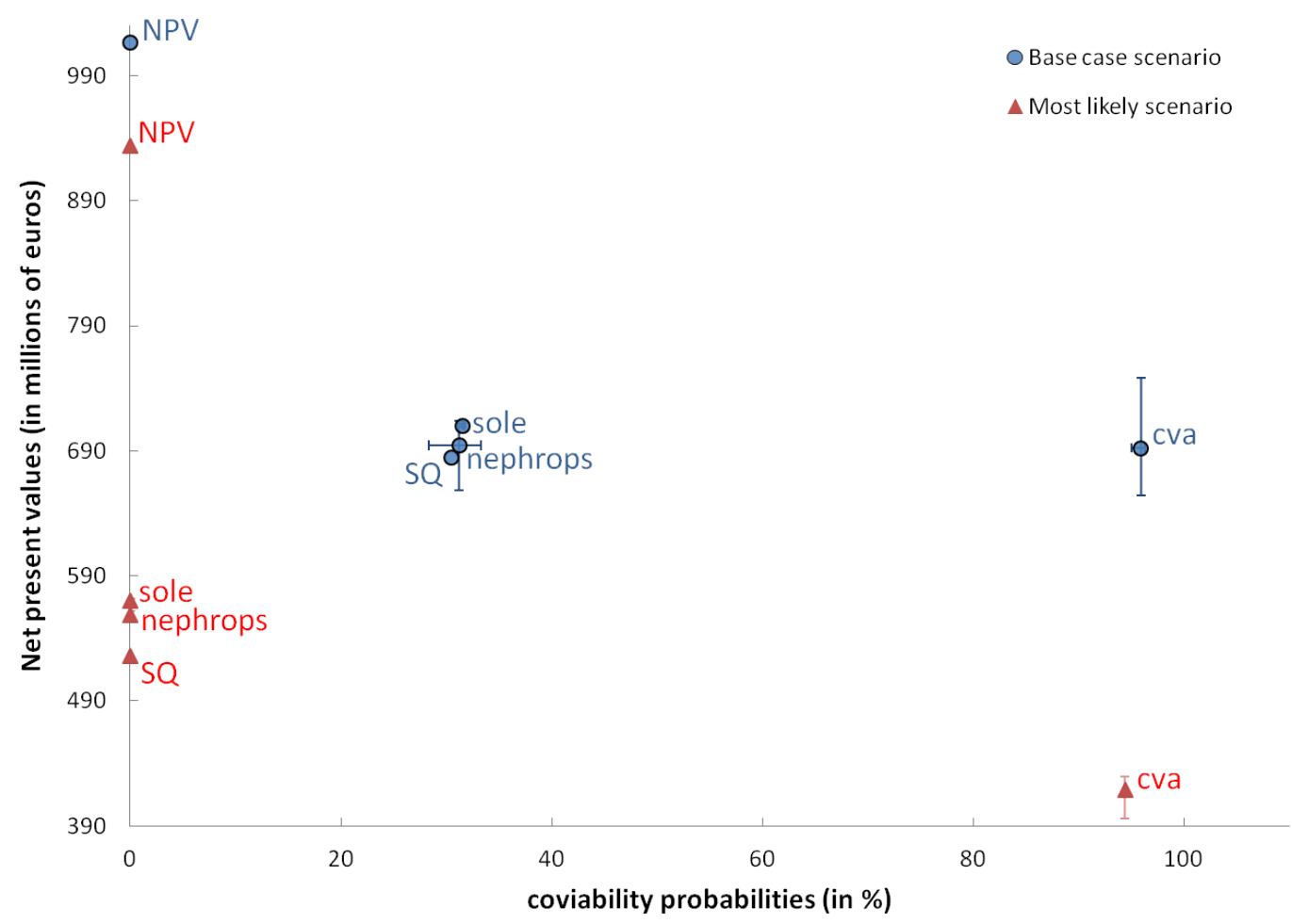

Figure 6: Mean net present values $\operatorname{NPV}(u)$ versus co-viability probabilities $\mathbb{P}_{\mathrm{CVA}}(u)$ of each management strategy under both fuel scenarios. The blue dots stand for the strategies under the base case scenario and the red triangles under the most likely scenario.

ing their recruitment. In other words, the ecological risk is low. By contrast, figures 8 and 9 show that the economic viability of the fishery appears threatened under this strategy. Indeed $\mathbb{P}_{\mathrm{EVA}}\left(u^{\mathrm{so}}\right)=31.1 \%$ under a base case fuel scenario and $\mathbb{P}_{\mathrm{EVA}}\left(u^{\mathrm{se}}\right)=0$ under a most likely scenario (i.e. the fuel price increase projection). The latter outcome implies that for every 1000 replicates of the strategy, at least one sub-fleet profit becomes negative during a period of time over the projection period. 

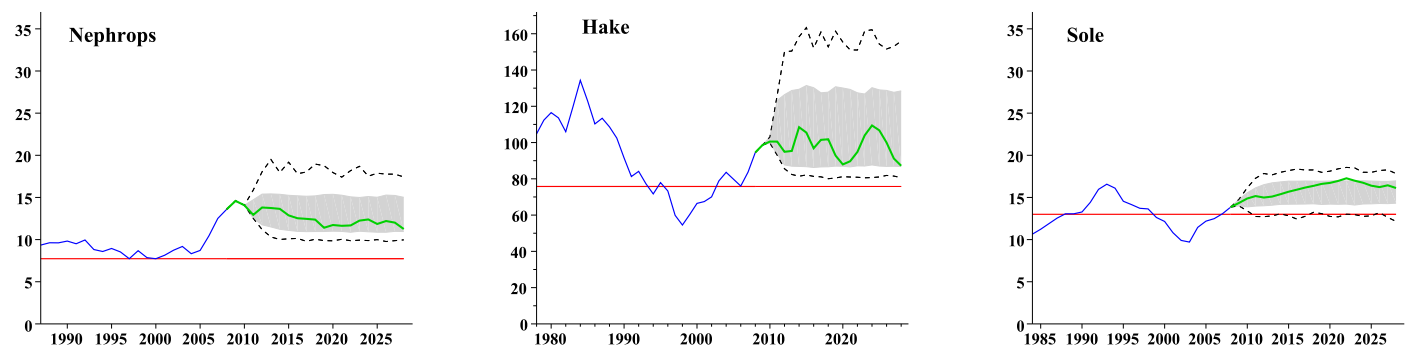

Figure 7: Trajectories of the spawning stock biomass $\operatorname{SSB}_{s}(t)$ of each species $s$ (in thousands of tonnes) with a status quo strategy (i.e. with $u_{f}^{\mathrm{sQ}}(t)=1$ for all $f$ ). The viability thresholds are in red (i.e. Bpa reference points by species). The set of possibilities that includes all of the 1000 simulated trajectories is represented by the dark dotted lines and the grey field includes $95 \%$ of the trajectories. The green line is one particular trajectory among the 1000 trajectories associated to the same set of $\omega($.$) and \widetilde{\omega}($.$) for each sub-figure of$ figures 7 to 9 . The lines in blue represent the estimated historical SSB for each species: Nephrops $(s=1)$, Hake $(s=2)$ and Sole $(s=3)$.

\subsection{NPV strategy : high total net present value but not economically viable}

As displayed by table 2 and figure 5, this strategy turns out to be ecologically viable with a strong population viability probability $\mathbb{P}_{\mathrm{PVA}}\left(u^{\mathrm{NPv}}\right)=100 \%$ as shown in figure 5 . Thus significant improvements in the status of stocks occur in the long run especially for Nephrops and Sole species. However, even though the global net present value of the fishery as a whole is higher than with other management strategies (c.f. figure 6), the NPV strategy is not economically viable for some sub-fleets, the profitability of which vanishes. This leads to a collapse of the economic viability probability, as defined in equation (15), with $\mathbb{P}_{\mathrm{EVA}}\left(u^{\mathrm{NPV}}\right)=0 \%$ under both scenarios (table 2 and figure 5), and results from the fact that the strategy requires these sub-fleets to become inactive $\left(u_{f}=0\right)$, e.g. the larger Nephrops trawlers or some of the various fish trawlers and Sole gill-netters as illustrated in figure 4. This result, based on the structure of interactions and economic and technical parameter values used in these simulations, seems to indicate that these sub-fleets 

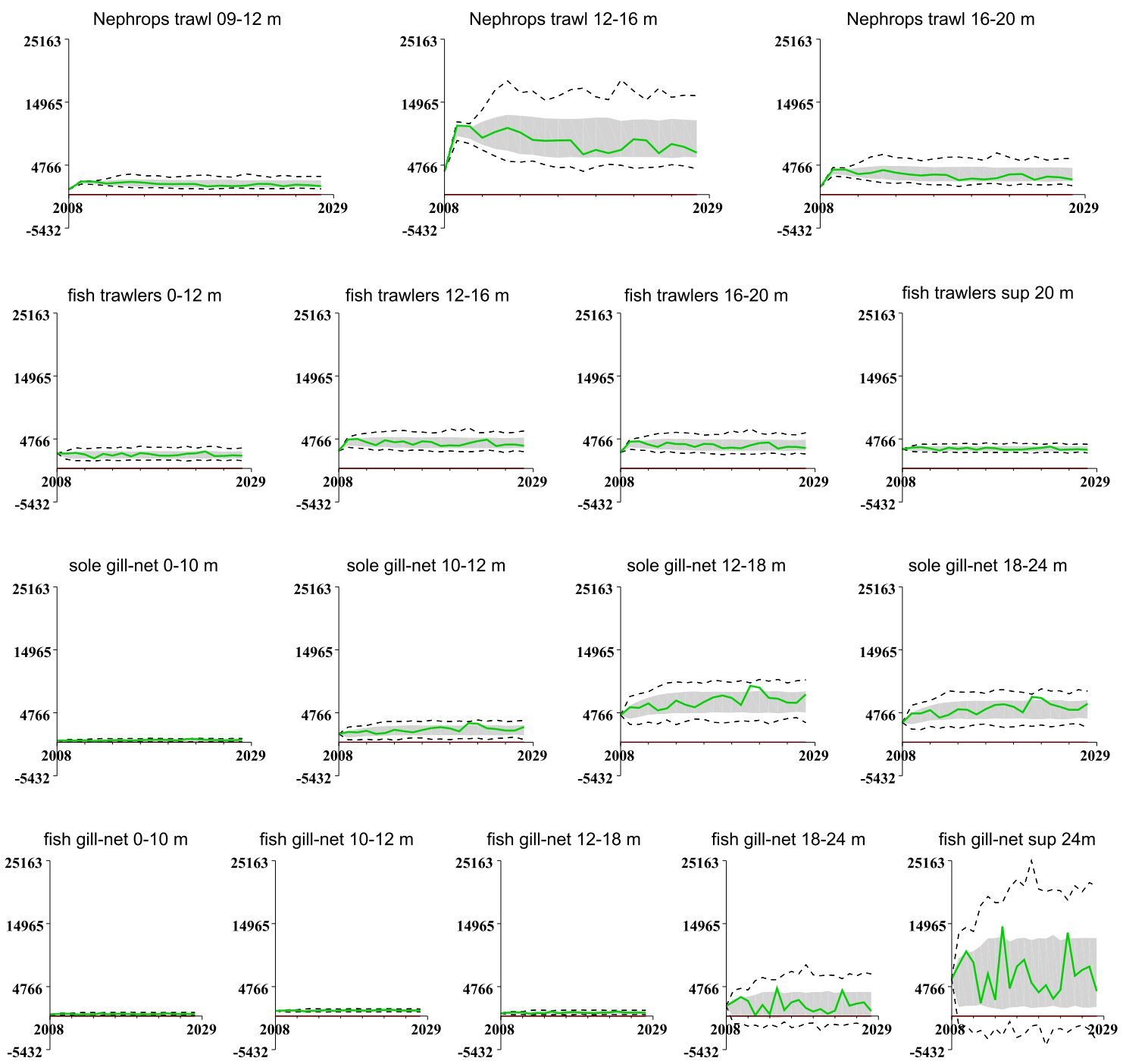

Figure 8: Trajectories of the profits $\pi_{f}(t)$ of each sub-fleet according to time $t$ under a base case fuel scenario $\mathrm{BC}$ with a status quo strategy (i.e. with $u_{f}^{\mathrm{se}}(t)=1$ for all $f$ ). The viability thresholds are in red (i.e. zero, strictly positive profits required). The set of possibilities that includes all of the 1000 simulated trajectories is represented by the dark dotted line and the grey field includes $95 \%$ of the trajectories. The green line is one particular trajectory among the 1000 trajectories associated to the same set of $\omega($.$) and \widetilde{\omega}($.$) for each$ sub-figure of figures 7 to 9 . 

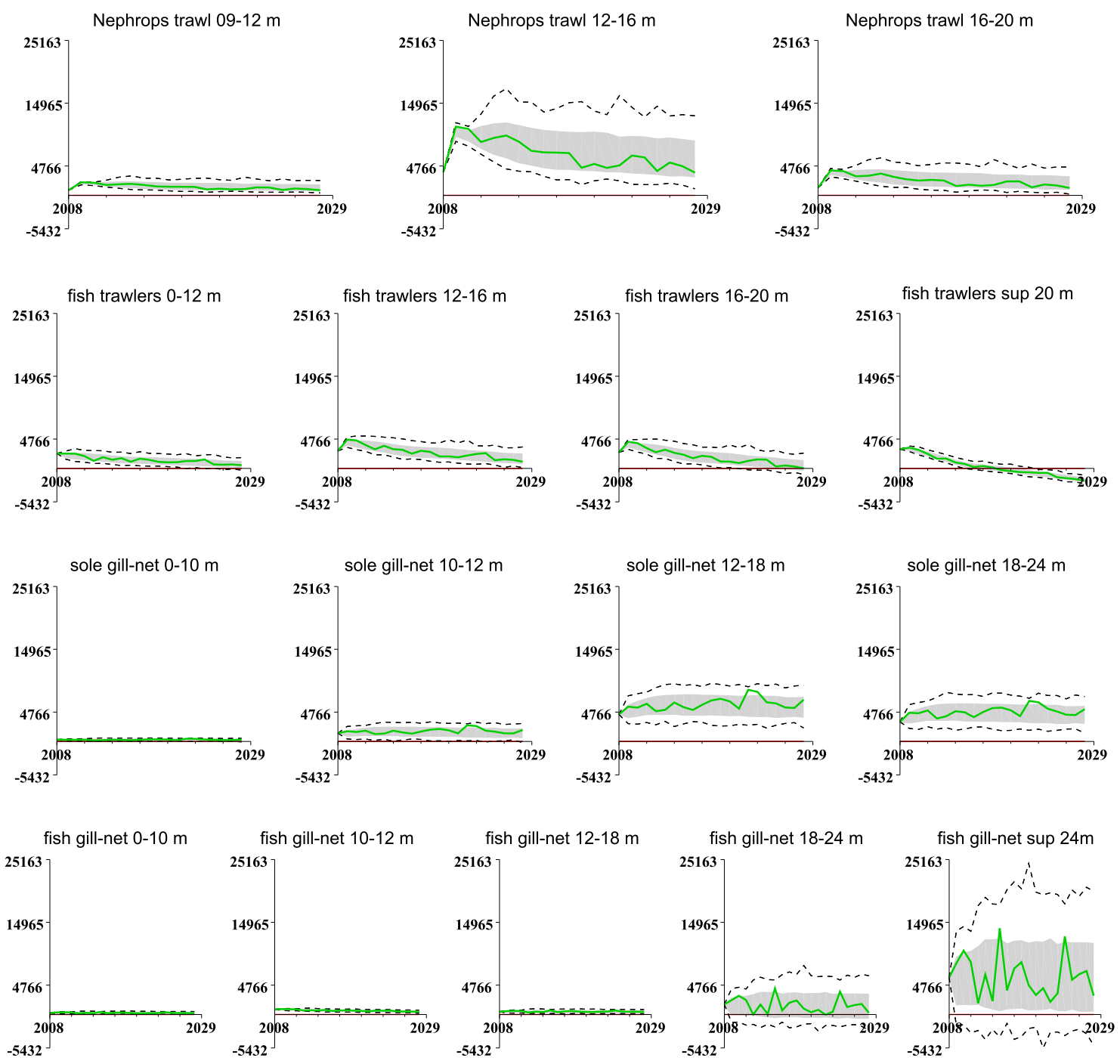

Figure 9: Trajectories of the profits $\pi_{f}(t)$ of each sub-fleet according to time $t$ under a most likely fuel scenario ML with a status quo strategy (i.e. with $u_{f}^{\mathrm{sQ}}(t)=1$ for all $f$ ). The viability thresholds are in red (i.e. zero, strictly positive profits required). The set of possibilities that includes all of the 1000 simulated trajectories is represented by the dark dotted line and the grey field includes $95 \%$ of the trajectories. The green line is one particular trajectory among the 1000 trajectories associated to the same set of $\omega($.$) and \widetilde{\omega}($.) for each sub-figure of figures 7 to 9 . 
are relatively less efficient than other sub-fleets in the model; hence their contribution to catches and landings under a NPV strategy would be reduced to zero. In other words, the lack of viable outcomes under such a NPV strategy is due to intra-fleet heterogeneity, in terms of technical efficiency, costs and prices. The various fish trawlers of 12-16 meters and greater than 20 meters are active and see their capacity increase under a base case scenario; however these sub-fleets become inactive under a most likely scenario, due to their sensitivity to fuel prices as they use important quantities of fuel.

\section{3. cva strategy: ecologically and economically viable}

The effort multipliers combinations $u^{\mathrm{cva}}$ associated to the cVA management strategy maximize the probability of co-viability, mixing ecological and economic constraints as defined in equations (12) and (14). As expected, this strategy is ecologically viable with guaranteed population viability $\left(\mathbb{P}_{\mathrm{PVA}}\left(u^{\mathrm{cvA}}\right)=100 \%\right)$ as displayed in figure 5; i.e. biomass trajectories lie above the precautionary thresholds $B_{s}^{\mathrm{pa}}$ for every species. Moreover the economic performance of this strategy is also high, with an economic viability probability superior to $95 \%\left(\mathbb{P}_{\mathrm{EVA}}\left(u^{\mathrm{cva}}\right) \geqslant 95 \%\right)$ as illustrated in the figure 5. In $95 \%$ of the cases, every sub-fleet exhibits strictly positive profit throughout time. As shown in figure 4, such bio-economic outcomes are obtained through redistributing fishing effort among the subfleets. While no sub-fleet is made inactive, the strategy leads to significant reductions in the capacity of some sub-fleets, mostly trawlers that have an important impact on modelled species. Moreover, to reduce economic risk (i.e. to increase the probability of economic viability), the sub-fleets with the most variability in their profit must decrease their capacity under this strategy. Figure 6 shows that while the profitability of each fleet is guaranteed and the economic risk is reduced, the global economic performance of the fishery (i.e. 
NPV) is smaller. Not surprisingly, the loss in NPV is stronger under a most likely scenario.

\subsection{Sole strategy: not economically viable}

The sol strategy involves mono-specific management targeting Sole as defined by equation (21). Hence only effort multipliers related to Sole gill-netters $(f=8,9,10,11)$ are affected as presented in figure 4. The results suggests that the sub-fleet of smaller Sole gill-netters $(f=8,9,10)$ should be favoured under such a strategy. This strategy is ecologically viable as $\mathbb{P}_{\mathrm{PVA}}\left(u^{\mathrm{SOL}}\right)=100 \%$ (figure 5). Similarly, the economic viability - in particular for the smallest Sole gill-netter sub-fleets - is slightly improved as shown by the figure 5 and table 2. However the strategy as a whole is not economically sustainable as the economic viability probability $\mathbb{P}_{\mathrm{EVA}}\left(u^{\mathrm{SoL}}\right)$ varies between 31.5 and $31.7 \%$ depending on the effort multipliers combinations for a base case fuel scenario and is equal to zero under a most likely scenario. Indeed, some sub-fleets, especially various fish gill-netters do not benefit from the strategy as their fishing effort remains fixed.

\subsection{Nephrops strategy: not economically viable}

The NEP strategy is a mono-specific management strategy targeting the Nephrops fishery only, as defined by equation (23). Hence only effort multipliers $u_{f}$ for Nephrops trawlers $f=1,2,3$ are impacted by this strategy, as shown in figure 4 . The results suggest that the sub-fleet of smaller vessels $f=1$ should be favoured while the sub-fleet of moderate size trawlers should see its capacity slightly reduced. This especially occurs under a most likely scenario. This strategy appears to be ecologically acceptable since it implies a high overall population viability probability $\left(98.4<\mathbb{P}_{\mathrm{PVA}}\left(u^{\mathrm{NEP}}\right)<98.7 \%\right)$, although some risks persist for Sole, like in the baseline sQ, as stressed by figure 5. As expected, the status 
of the Nephrops stock is improved, especially under a most likely scenario where larger Nephrops trawlers are subjected to more important capacity reduction. Similarly, the economic viability for the Nephrops trawlers sub-fleets is maintained. However such a mono specific strategy is not co-viable as defined here, since the profitability of other sub-fleets, particularly for various fish gill-netters, is threatened, as in the status quo strategy. Note however that NEP and sol strategies display higher net present value than the status quo strategy as shown in figure 6 under both fuel scenarios.

\section{Discussion}

\subsection{Decision support for the Bay of Biscay mixed fishery}

The modelling approach we propose to address trade-offs in managing the French Bay of Biscay demersal fishery allows us to directly compare the biological and economic outcomes of single-stock management strategies with the outcomes of management strategies defined for the mix of species and fleets as a whole. More specifically, we can compare management strategies which would attempt to manage the Nephrops fishery or the Sole fishery separately - as has historically been the case until recent years - to two alternative fishery-wide management approaches aimed at (i) maximizing economic yield, or (ii) adjusting the capacity of fishing sub-fleets so that both the biological and the economic viability constraints can be met for every single species and sub-fleet.

Based on our simulations and regarding the species and fleets modelled, it appears that the role of ecological constraints in determining viable management strategies is weak as compared to economic constraints. This is confirmed by assessing the impact of the

ecological constraints on the different strategies $u$, through calculation of the difference 
$\mathbb{P}_{\mathrm{EVA}}(u)-\mathbb{P}_{\mathrm{CVA}}(u)$ between the probability of economic viability and the probability of coviability based on values of the table 2 . The fact that for strategies SQ, NPV and CVA, this difference is zero, suggests that the marginal impact of the ecological constraints is weak. In other words, given the bio-economic situation of the fishery as captured in our model for the late 2000s, sustainability risks in the fishery are rather economic.

Based on the data used to calibrate the model and economic assumptions of the model (in particular assumptions on incomes from other species and on constant annual costs per vessel), simulation results show that the status quo strategy - consisting of maintaining fishing effort of all sub-fleets at their levels of the 2008 baseline - is not economically viable. This outcome holds especially true under a most likely scenario where fuel increase projection are taken into account. The results indicate that, given the status of the species and fleets in 2008, and the nature of the technical interactions between fleets through bycatch and discards, there appears to be excess capacity in the fishery as a whole. Hence all alternative management strategies tested lead to some reduction in the capacity of the fleets. These results are not surprising as the Bay of Biscay demersal fisheries have suffered of chronic overcapacity (EC, 2009). These fisheries are currently managed through total allowable catch limits, and a limited entry system for Nephrops and Sole fisheries. However, management of the fisheries has historically been carried out per species, rather than in an integrated, more cooperative, approach. Therefore, the current situation in the fishery is probably relatively close to our simulated mono-specific management strategies, in which attempts are made to maximize the profits of different fleets individually, with no consideration for the global profit in the fishery as a whole. Under the new European management plan, future multi-species management definitions (EC, 2009) should improve 
the management of the Bay of Biscay demersal fisheries. The objective of such integrated management strategies could for example be to achieve Maximum Economic Yield (Grafton et al., 2010) at the scale of the fishery. However, our research highlights the existence of an alternative co-viability strategy which could be seen as more acceptable as it entails less drastic adjustments in capacity across fleets and regions, at least in a transition phase. The simulations allow to explore the trade-offs associated with alternative management approaches. Single-species management strategies improve the bio-economic status for the specific fishery they target, but do not achieve satisfactory results at the global scale. While the Sole management strategy achieves ecological viability, it leads some sub-fleets other than the Sole gill-netters to become unprofitable. Depending on its effort multipliers combinations, the Nephrops management strategy produces better fishery-wide results as regards the economic performance of the fleets, but still induces negative profits for some sub-fleets, as well as a moderate level of risk that the ecological viability of the fishery will not be guaranteed. The two fishery-wide strategies we examine produce strongly contrasted outcomes. The net present value strategy achieves its objective of maximizing high level of economic performance for the overall fishery. Despite the management systems in place, and a series of decommissioning plans which have been aimed at reducing the capacity of these fleets, the fishery seems far from realising its Maximum Economic Yield objective. Our approach provides an explanation for this, based on the observation that a strategy aimed at maximizing the Net Present Value of profits derived from the fishery as a whole would actually lead to quite heterogeneous impacts on the fleets and sub-fleets. This management strategy can thus not be considered as economically viable in the sense we have defined for the purpose of this analysis. This is because the strategy leads to stop 
certain sub-fleets entirely from fishing, in particular larger Nephrops trawlers, various fish trawlers and certain sub-fleets of Sole gill-netters. Such an outcome is a direct result of the differences in economic efficiency between sub-fleets and technical interactions between them that were assumed in the model. The fact that this makes the NPV strategy non-viable can be interpreted as capturing the resistance which may develop against such a strategy from the segments and regions of the fishery which would be negatively impacted. The need to capture such constraints in bio-economic simulations of the potential benefits of alternative fisheries management strategies has been increasingly recognised (see Martinet et al. (2010) and Péreau et al. (2012) for recent applications).

Simulation results show that the co-viability strategy can be achieved by a number of combinations of capacity adjustments, which all allow the ecological and economic viability constraints to be met for all species and sub-fleets. The strategy however also points to the need for a global reduction of capacity even if reallocations in effort are not quite as drastic as the one suggested by the NPV strategy, and allow some activity to be maintained in all sub-fleets. This strategy might be expected to more easily achieve consensus among the multiple stakeholders involved in the fishery. Indeed, the NPV strategy does not provide much flexibility in the selection of capacity reduction across fleets, so leaves little room for negotiations. Circumstances under which such a strategy might be expected to be more easily adopted would be where the owners of vessels belonging to the sub-fleets which remain active and benefit from the adjustment could buy-out or compensate the owners of those vessels that are requested to leave (Clark et al., 2005, Martell et al., 2009). In this vein, Holland et al. (1999), Guyader et al. (2004), Squires (2010) give examples where buybacks of vessels, licences, gear, access, and other use and 
property rights can be considered as a useful transition policy tool to address overcapacity, overexploitation of fish stocks and distributional issues in fisheries.

The assumption of increasing fuel price, which is likely to occur, is detrimental to the all the bio-economic outcomes of simulations, as captured in figures 5 and 6 . However, it does not change the nature of the qualitative outcomes and analysis.

\subsection{Co-viability as step towards integrated management for mixed fisheries}

It is increasingly recognised that a wide range of stakeholders are involved in fisheries and their management, including industrial, artisanal, subsistence and recreational fishermen, suppliers and workers in allied industries, managers, scientists, environmentalists, economists, public decision makers and the general public (Hilborn, 2007). Each of these groups has an interest in particular outcomes from fisheries and the outcomes that are considered desirable by one stakeholder may be undesirable to another group. The consideration of this multi-dimensional nature of marine fisheries management appears as an unavoidable reality, which should influence the nature of decision-support tools used to assist in the decision-making processes associated with the selection of fisheries regulations. The bio-economic modelling framework we propose offers both formal recognition of the multi-objective nature of management strategies, and means to integrate this with current understanding of the dynamics of a mixed fisheries system, in assessing the trade-offs associated with alternative approaches to regulate such systems. The model illustrates the benefits of formally combining integrated bio-economic modelling with the multi-criteria evaluation underlying the viability framework of analysis. This allows management strategies to be assessed from a range of perspectives including the standard criteria of fish stock

preservation and fishery-level economic efficiency, as well as other dimensions which have 
less frequently been included in formal bio-economic modelling approaches, such as concern for the maintenance of active and profitable fishing fleets. In addition, the viability approach allows characterizing management strategies in terms of their degree of flexibility, with some management strategies offering more options than others in terms of implementation. Since alternative options are bound to have different distributional impacts, it could be expected that strategies offering more alternatives may stand better chances of being adopted, as they provide greater "bargaining space" for the stakeholders to reach consensus. In the simulation results obtained in this study, this is the case of the cva strategy, which seems to provide greater adaptation options than the net present value strategy. Such characteristics of management strategies would appear particularly important in the context of mixed fisheries management, which application of the ecosystem approach requires to be managed as a whole, rather than in separate component fisheries. It is likely that models allowing alternative management strategies to be compared in this respect will have greater chances to be adopted as decision support tools in the future.

\subsection{Perspectives}

To go further, several authors (e.g. Mullon et al. (2004), Cury et al. (2005), Chapel et al. (2008)) have proposed the viability approach as a well-suited modelling framework for Ecosystem-Based Fishery Management (EBFM). EBFM must manage targeted species in the context of the overall state of the system, habitat, protected species, and non targeted species. The dynamics considered can potentially include complex mechanisms such as trophic interactions, competition, metapopulations dynamics or economic investment process to quote a few. Here the focus is on technical interactions through a multi-fleets and multi-species context, in particular the bycatch of hake by trawlers. For this specific case- 
study, the comparison of mono-specific approaches for Sole or Nephrops with the more integrated perspective of cVA stresses the importance of integrating management across the complex set of interactions that define these fisheries. Several expansions of this bioeconomic model could be considered which could provide useful insights in support of an ecosystem approach to the management of the Bay of Biscay demersal fisheries. This could include the addition of other important commercial demersal species - for example Anglerfish (Lophius piscatorius and L. budegassa) which is another key species landed by some fleets. Moreover, many studies relating to trawling show that this fishing technique can also impact habitats, through re-suspension of the sediments, and impacts on the structure of benthic communities (Collie et al., 2000) that entail variations inthe ecological production processes (Jennings et al., 2001). Therefore it could be important to also consider the ecological impacts of trawling in the evaluation of management strategies, which would mean including both the interactions between fishing levels and patterns across sub-

fleets and the benthic habitats, and identifying levels of acceptable impacts on the basis of which to set additional viability constraints. On the human side of the analysis, it could also be important to explicitly capture the Spanish and Belgian fleets, if the approach is to become relevant as a decision-support tool for joint management of the Bay of Biscays fisheries. In addition, the assumption of constant effort over time should be relaxed in order to promote more adaptive strategies.

\section{Acknowledgement}

This work has been carried out with the support of the French Research Agency ANR (Agence National pour la Recherche) through the research program entitled Adhoc. We 
are grateful to Mathieu Merzeraud and Christelle Le Grand for data analyses and to two anonymous reviewers for their helpful comments on an earlier version of the manuscript.

\section{References}

Alverson, D., Freeberg, M., Murawski, S., Pope, J., 1994. A global assessment of fisheries bycatch and discards. FAO Fisheries Technical Paper 339, 233.

Aubin, J., 1990. A survey of viability theory. SIAM Journal on Control and Optimization $28(4), 749-788$.

Baumgärtner, S., Quaas, M., 2009. Ecological-economic viability as a criterion of strong sustainability under uncertainty. Ecological Economics 68 (7), 2008-2020.

Bene, C., Doyen, L., 2008. Contribution values of biodiversity to ecosystem performances: A viability perspective. Ecological Economics 68 (1-2), 14-23.

Béné, C., Doyen, L., Gabay, D., 2001. A viability analysis for a bio-economic model. Ecological Economics 36 (3), 385-396.

CAS, 2012. Les secteurs de la nouvelle croissance : une projection á l'horizon 2030. Tech. rep., Centre d'analyse stratégique.

Chapel, L., Deffuant, G., Martin, S., Mullon, C., 2008. Defining yield policies in a viability approach. Ecological Modelling 212 (1-2), 10-15.

Cheung, W., Sumaila, U., 2008. Trade-offs between conservation and socio-economic objectives in managing a tropical marine ecosystem. Ecological Economics 66 (1), 193210. 
Clark, C., 1976. Mathematical bioeconomics: the optimal management of renewable resources. Wiley, New York.

Clark, C., Munro, G., Sumaila, U., 2005. Subsidies, buybacks, and sustainable fisheries. Journal of Environmental Economics and Management 50 (1), 47-58.

Collie, J., Hall, S., Kaiser, M., Poiner, I., 2000. A quantitative analysis of fishing impacts on shelf-sea benthos. Journal of Animal Ecology 69 (5), 785-798.

Cury, P., Mullon, C., Garcia, S., Shannon, L., 2005. Viability theory for an ecosystem approach to fisheries. ICES Journal of Marine Science 62 (3), 577.

Daurès, F., Rochet, M., Van Iseghem, S., Trenkel, V., 2008. An integrated assessment of the ecological and economical status of fisheries - application to the french fisheries in the bay of biscay. In: Proceedings of the Fourteenth Biennial Conference of the International Institute of Fisheries Economics and Trade (IIFET). Nha Trang, Vietnam.

De Lara, M., Doyen, L., 2008. Sustainable management of natural resources: mathematical models and methods. Springer Verlag.

De Lara, M., Doyen, L., Guilbaud, T., Rochet, M., 2007. Is a management framework based on spawning-stock biomass indicators sustainable? A viability approach. ICES Journal of Marine Science 64 (4), 761.

Doyen, L., De Lara, M., 2010. Stochastic viability and dynamic programming. Systems \& Control Letters 59 (10), 629-634.

Doyen, L., Martinet, V., 2012. Maximin, viability and sustainability. Journal of Economic Dynamics and Control. 
Doyen, L., Thébaud, O., Béné, C., Martinet, V., Gourguet, S., Bertignac, M., Fifas, S., Blanchard, F., 2012. A stochastic viability approach to ecosystem-based fisheries management. Ecological Economics 75, 32-42.

EC, 2009. Green paper: Reform of the common fisheries policy. Brussels: European Commission, COM (2009) 163 final, 27.

Eisenack, K., Scheffran, J., Kropp, J., 2006. Viability analysis of management frameworks for fisheries. Environmental Modeling and Assessment 11 (1), 69-79.

Fleming, P., Purshouse, R., 2002. Evolutionary algorithms in control systems engineering: a survey. Control engineering practice 10 (11), 1223-1241.

Garcia, D., Prellezo, R., Santurtun, M., Arregi, L., 2011. Winners and losers of a technical change: A case study of long-term management of the northern european hake. Fisheries Research 110 (1), 98-110.

Grafton, R., Kompas, T., Chu, L., Che, N., 2010. Maximum economic yield. Australian Journal of Agricultural and Resource Economics 54 (3), 273-280.

Guéguen, J., Charuau, A., 1975. Essai de dtermination du taux de survie des langoustines hors taille rejetées lors des opérations de pêche commerciale. ICES CM 1975/K (12).

Guyader, O., Daurès, F., Fifas, S., et al., 2004. A bioeconomic analysis of the impact of decommissioning programs: application to a limited-entry french scallop fishery. Marine Resource Economics 19 (2), 225-242.

Hall, S., Mainprize, B., 2004. Towards ecosystem-based fisheries management. Fish and Fisheries 5 (1), 1-20. 
Hilborn, R., 2007. Defining success in fisheries and conflicts in objectives. Marine Policy $31(2), 153-158$.

Holland, D., Gudmundsson, E., Gates, J., 1999. Do fishing vessel buyback programs work: a survey of the evidence. Marine Policy 23 (1), 47-69.

ICES, 2009. Report of the working group on the assessment of southern shelf stocks of hake, monk and megrim (wghmm). ICES Headquarters, Copenhagen, 537.

ICES, 2010. Report of the working group on the assessment of southern shelf stocks of hake, monk and megrim (wghmm). Bilbao, Spain. ICES CM 2010/ACOM:11., 599.

IEA, 2010. World energy outlook. Tech. rep., Paris, OECD/IEA.

Jennings, S., Dinmore, T., Duplisea, D., Warr, K., Lancaster, J., 2001. Trawling disturbance can modify benthic production processes. Journal of Animal Ecology 70 (3), $459-475$.

Kell, L., Mosqueira, I., Grosjean, P., Fromentin, J., Garcia, D., Hillary, R., Jardim, E., Mardle, S., Pastoors, M., Poos, J., et al., 2007. Flr: an open-source framework for the evaluation and development of management strategies. ICES Journal of Marine Science: Journal du Conseil 64 (4), 640-646.

Kempf, A., 2010. Ecosystem approach to fisheries in the European context-history and future challenges. Journal of Applied Ichthyology 26, 102-109.

Le Loc'h, F., Hily, C., 2005. Stable carbon and nitrogen isotope analysis of nephrops norvegicus/merluccius merluccius fishing grounds in the bay of biscay (northeast atlantic). Canadian Journal of Fisheries and Aquatic Sciences 62 (1), 123-132. 
Lebègue, D. c., 2005. Révision du taux d'actualisation des investissements publics. Commissariat Général du Plan, 112.

Macher, C., Boncoeur, J., 2010. Optimal Selectivity and Effort Cost A Simple Bioeconomic Model with an Application to the Bay of Biscay Nephrops Fishery. Marine Resource Economics 25 (2), 213-232.

Macher, C., Guyader, O., Talidec, C., Bertignac, M., 2008. A cost-benefit analysis of improving trawl selectivity in the case of discards: The Nephrops norvegicus fishery in the Bay of Biscay. Fisheries Research 92 (1), 76-89.

Macher, C., Merzéréaud, M., Le Grand, C., Frésard, M., Bertignac, M., Fifas, S., Guyader, O., Biais, G., Lissardy, M., Jadaud, A., Le Corre, G., Frangoudes, K., Daurès, F., Van Iseghem, S., Raveau, A., 2011. Groupe de travail partenarial pour la construction d'outils bio-économiques d'aide à la décision pour l'aménagement des pêcheries. Publications électroniques Amure, Série Rapports R-21-2011, 44.

Mardle, S., Pascoe, S., 2000. Use of evolutionary methods for bioeconomic optimization models: an application to fisheries. Agricultural Systems 66 (1), 33-49.

Martell, S., Walters, C., Sumaila, U., 2009. Industry-funded fishing license reduction good for both profits and conservation. Fish and Fisheries 10 (1), 1-12.

Martinet, V., Doyen, L., 2007. Sustainability of an economy with an exhaustible resource: a viable control approach. Resource and Energy Economics 29 (1), 17-39.

Martinet, V., Thébaud, O., Doyen, L., 2007. Defining viable recovery paths toward sustainable fisheries. Ecological Economics 64 (2), 411-422. 
Martinet, V., Thébaud, O., Rapaport, A., 2010. Hare or tortoise? trade-offs in recovering sustainable bioeconomic systems. Environmental Modeling and Assessment 15 (6), 503-517.

Morris, W., Doak, D., 2002. Quantitative conservation biology: theory and practice of population viability analysis. Sinauer Associates Sunderland, Massachusetts.

Mullon, C., Cury, P., Shannon, L., 2004. Viability model of trophic interactions in marine ecosystems. Natural Resource Modeling 17 (1), 71-102.

Murua, H., Quincoces, I., García, D., Korta, M., 2010. Is the northern european hake, $;$ i $i$ merluccius merluccius $i / i_{i}$, management procedure robust to the exclusion of reproductive dynamics? Fisheries Research 104 (1), 123-135.

Nøstbakken, L., Thebaud, O., Sørensen, L., 2011. Investment behaviour and capacity adjustment in fisheries: a survey of the literature. Marine Resource Economics 26 (2), 95-117.

O’Brien, C., Maxwell, D., Roel, B., Basson, M., 2002. A segmented regression approach to the precautionnary approach - the case of the thames estuary (or blackwater) herring. Working document ICES Study Group on the Further Development of the Precautionary Approach to Fishery Management. Lisbon, Portugal.

Péreau, J., Doyen, L., Little, R., Thébaud, O., 2012. The triple bottom line: Meeting ecological, economic and social goals with individual transferable quotas. Journal of Environmental Economics and Management 63 (3), 419-434. 
Pikitch, E., Santora, C., Babcock, E., Bakun, A., Bonfil, R., Conover, D., Dayton, P., Doukakis, P., Fluharty, D., Heneman, B., et al., 2004. Ecology: ecosystem-based fishery management. Science 305 (5682), 346-347.

Plagányi, É., 2007. Models for an ecosystem approach to fisheries. FAO Fisheries Technical Paper (477).

Portney, P., Weyant, J., 1999. Discounting and intergenerational equity.

Prellezo, R., Accadia, P., Andersen, J., Andersen, B., Buisman, E., Little, A., Nielsen, J., Poos, J., Powell, J., Röckmann, C., 2012. A review of eu bio-economic models for fisheries: The value of a diversity of models. Marine Policy 36 (2), 423-431.

Punt, A., Smith, A., 1999. Harvest strategy evaluation for the eastern stock of gemfish (rexea solandri). ICES Journal of Marine Science: Journal du Conseil 56 (6), 860-875.

Quinn, T., Deriso, R., 1999. Quantitative fish dynamics. Oxford University Press, USA.

Raveau, A., Macher, C., Méhault, S., Merzéréaud, M., Le Grand, C., Guyader, O., Bertignac, M., Fifas, S., Guillen, J., 2012. A bio-economic analysis of experimental selective devices in the norway lobster (Nephrops norvegicus) fishery in the bay of biscay. Aquatic Living Resources 25 (in Press).

Sanchirico, J., Smith, M., Lipton, D., 2008. An empirical approach to ecosystem-based fishery management. Ecological Economics 64 (3), 586-596.

Sathianandan, T., Jayasankar, J., 2009. Managing marine fishery in kerala through simulation using surplus production model, genetic algorithm and spectral methods. Indian Journal of Fisheries 56 (3), 163-168. 
Squires, D., 2010. Fisheries buybacks: a review and guidelines. Fish and Fisheries 11 (4), $366-387$.

STECF, 2008. Northern hake long-term management plan impact assessment (sgbre-0705). Tech. rep., European Commision, Brussels.

Ye, Y., Cochrane, K., Bianchi, G., Willmann, R., Majkowski, J., Tandstad, M., Carocci, F., 2012. Rebuilding global fisheries: the world summit goal, costs and benefits. Fish and Fisheries. 
Appendix

\section{AppendixA. Bio-economic model parameters}

This appendix displays the values of the biological and economic parameters used to calibrate the bio-economic model presented in section 2.2. Tables A.1 to A.3 show the parameters values of stock dynamics and average market price by species and by age. Tables A.4 to A.6 give the estimated values of fishing mortalities by species, by age and by sub-fleet. The biological reference points $B_{s}^{\mathrm{lim}}, B_{s}^{\mathrm{pa}}$ and average historical recruitment $\bar{R}_{s}$ for every species are displayed in table A.7. Tables A.8 to A.10 show the estimated values of discard rates by species, by age and by sub-fleet. And tables A.11 and A.12 give the values of the economic parameters and fishing effort in 2008 for every sub-fleet.

Table A.1: Nephrops parameters $(s=1), t_{0}=2008$. Source: ICES; Ifremer, SIH, DPMA .

\begin{tabular}{c|lllllllll} 
Age a & 1 & 2 & 3 & 4 & 5 & 6 & 7 & 8 & 9 \\
\hline Initial abund. $\mathrm{N}_{1, a}\left(t_{0}\right)\left(* 10^{3}\right.$ indv) & 642616 & 650008 & 328988 & 180528 & 65279 & 23173 & 8304 & 4257 & 4679 \\
Maturity $\gamma_{1, a}$ & 0 & 0 & 0,75 & 1 & 1 & 1 & 1 & 1 & 1 \\
Mean weight $\left(\mathrm{kg} \backslash\right.$ indv) $v_{1, a}$ & 0,004 & 0,009 & 0,016 & 0,027 & 0,037 & 0,046 & 0,058 & 0,068 & 0,091 \\
Natural mortality $M_{1, a}$ & 0,3 & 0,3 & 0,25 & 0,25 & 0,25 & 0,25 & 0,25 & 0,25 & 0,25 \\
Age price coefficient $\Upsilon_{1, a}$ & 0.97 & 0.97 & 0.87 & 0.87 & 0.87 & 0.87 & 1.4 & 1.4 & 1.68 \\
Mean price $(€ \mathrm{~kg}) \mu_{1}^{P}$ & 10.46 & & & & & & & &
\end{tabular}

Table A.2: Hake parameters $(s=2), t_{0}=2008$. Source: ICES; Ifremer, SIH, DPMA.

\begin{tabular}{c|lllllllll} 
Age a & 0 & 1 & 2 & 3 & 4 & 5 & 6 & 7 & $8+$ \\
\hline Initial abund. $\mathrm{N}_{2, a}\left(t_{0}\right)\left(* 10^{3}\right.$ indv) & 236062 & 132608 & 61571 & 25195 & 5219 & 1606 & 497 & 162 & 45 \\
Maturity $\gamma_{2, a}$ & 0 & 0,11 & 0,73 & 0,93 & 0,99 & 1 & 1 & 1 & 1 \\
Mean weight $\left(\mathrm{kg} \backslash\right.$ indv) $v_{2, a}$ & 0,029 & 0,25 & 0,716 & 1,572 & 2,503 & 3,452 & 4,393 & 5,773 & 6,747 \\
Natural mortality $M_{2, a}$ & 0,4 & 0,4 & 0,4 & 0,4 & 0,4 & 0,4 & 0,4 & 0,4 & 0,4 \\
Age price coefficient $\Upsilon_{2, a}$ & 0.54 & 0.54 & 0.79 & 1.11 & 1.49 & 1.87 & 1.87 & 1.87 & 1.87 \\
Mean price $(€ \mathrm{~kg}) \mu_{2}^{P}$ & 3.69 & & & & & & & &
\end{tabular}


Table A.3: Sole parameters $(s=3), t_{0}=2008$. Source: ICES; Ifremer, SIH, DPMA.

\begin{tabular}{c|lllllll} 
Age a & 2 & 3 & 4 & 5 & 6 & 7 & $8+$ \\
\hline Initial abund. $\mathrm{N}_{3, a}\left(t_{0}\right)\left(* 10^{3}\right.$ indv $)$ & 23191 & 17416 & 10707 & 4864 & 3425 & 2627 & 2590 \\
Maturity $\gamma_{3, a}$ & 0,32 & 0,83 & 0,97 & 1 & 1 & 1 & 1 \\
Mean weight $\left(\mathrm{kg} \backslash\right.$ indv) $v_{3, a}$ & 0,189 & 0,241 & 0,297 & 0,352 & 0,423 & 0,449 & 0,599 \\
Natural mortality $M_{3, a}$ & 0,1 & 0,1 & 0,1 & 0,1 & 0,1 & 0,1 & 0,1 \\
Age price coefficient $\Upsilon_{3, a}$ & 0.69 & 0.82 & 0.99 & 1.14 & 1.14 & 1.14 & 1.12 \\
Mean price $(€ \mathrm{~kg}) \mu_{3}^{P}$ & 12.41 & & & & & &
\end{tabular}

Table A.4: The values of fishing mortality on Nephrops $(s=1): F_{1, a, f}\left(t_{0}\right)$. Source: ICES; Ifremer, SIH, 2008.

\begin{tabular}{|c|c|c|c|c|c|c|c|c|c|c|}
\hline Fleets & sub-fleets Age a & 1 & 2 & 3 & 4 & 5 & 6 & 7 & 8 & 9 \\
\hline \multirow{3}{*}{$\begin{array}{c}\text { Nephrops } \\
\text { trawlers }\end{array}$} & 09-12 m & 0.002 & 0.027 & 0.039 & 0.039 & 0.034 & 0.035 & 0.035 & 0.035 & 0.035 \\
\hline & $12-16 \mathrm{~m}$ & 0.01 & 0.161 & 0.233 & 0.232 & 0.205 & 0.206 & 0.207 & 0.209 & 0.209 \\
\hline & $16-20 \mathrm{~m}$ & 0.004 & 0.057 & 0.083 & 0.083 & 0.073 & 0.073 & 0.074 & 0.074 & 0.074 \\
\hline \multirow{4}{*}{$\begin{array}{c}\text { Various fish } \\
\text { trawlers }\end{array}$} & $0-12 \mathrm{~m}$ & 0 & 0.003 & 0.004 & 0.004 & 0.004 & 0.004 & 0.004 & 0.004 & 0.004 \\
\hline & $12-16 \mathrm{~m}$ & 0.002 & 0.03 & 0.044 & 0.043 & 0.038 & 0.039 & 0.039 & 0.039 & 0.039 \\
\hline & $16-20 \mathrm{~m}$ & 0.002 & 0.035 & 0.051 & 0.051 & 0.045 & 0.045 & 0.045 & 0.046 & 0.046 \\
\hline & $\sup 20 \mathrm{~m}$ & 0 & 0.008 & 0.011 & 0.011 & 0.01 & 0.01 & 0.01 & 0.01 & 0.01 \\
\hline \multirow{4}{*}{$\begin{array}{c}\text { Sole } \\
\text { gill-netters }\end{array}$} & $0-10 \mathrm{~m}$ & 0 & 0 & 0 & 0 & 0 & 0 & 0 & 0 & 0 \\
\hline & $10-12 \mathrm{~m}$ & 0 & 0 & 0 & 0 & 0 & 0 & 0 & 0 & 0 \\
\hline & $12-18 \mathrm{~m}$ & 0 & 0 & 0 & 0 & 0 & 0 & 0 & 0 & 0 \\
\hline & $18-24 \mathrm{~m}$ & 0 & 0 & 0 & 0 & 0 & 0 & 0 & 0 & 0 \\
\hline \multirow{5}{*}{$\begin{array}{l}\text { Various fish } \\
\text { gill-netters }\end{array}$} & $0-10 \mathrm{~m}$ & 0 & 0 & 0 & 0 & 0 & 0 & 0 & 0 & 0 \\
\hline & $10-12 \mathrm{~m}$ & 0 & 0 & 0 & 0 & 0 & 0 & 0 & 0 & 0 \\
\hline & $12-18 \mathrm{~m}$ & 0 & 0 & 0 & 0 & 0 & 0 & 0 & 0 & 0 \\
\hline & $18-24 \mathrm{~m}$ & 0 & 0 & 0 & 0 & 0 & 0 & 0 & 0 & 0 \\
\hline & $\sup 24 \mathrm{~m}$ & 0 & 0 & 0 & 0 & 0 & 0 & 0 & 0 & 0 \\
\hline Other fleets & & 0.001 & 0.015 & 0.021 & 0.021 & 0.019 & 0.019 & 0.019 & 0.019 & 0.019 \\
\hline
\end{tabular}


Table A.5: The values of fishing mortality on Hake $(s=2): F_{2, a, f}\left(t_{0}\right)$. Source: ICES; Ifremer, SIH, 2008.

\begin{tabular}{cc|lllllllll} 
Fleets & Age a & 0 & 1 & 2 & 3 & 4 & 5 & 6 & 7 & $8+$ \\
\hline \multirow{2}{*}{ Nephrops } & $09-12 \mathrm{~m}$ & 0.009 & 0.004 & 0.001 & 0 & 0 & 0 & 0 & 0 & 0 \\
trawlers & $12-16 \mathrm{~m}$ & 0.051 & 0.026 & 0.006 & 0.001 & 0.001 & 0.001 & 0.001 & 0.001 & 0.002 \\
& $16-20 \mathrm{~m}$ & 0.033 & 0.016 & 0.004 & 0 & 0.001 & 0.001 & 0.001 & 0.001 & 0.001 \\
\hline \multirow{3}{*}{ Various fish } & $0-12 \mathrm{~m}$ & 0.016 & 0.013 & 0.006 & 0.002 & 0.002 & 0.001 & 0 & 0 & 0 \\
trawlers & $12-16 \mathrm{~m}$ & 0.018 & 0.015 & 0.007 & 0.002 & 0.003 & 0.001 & 0 & 0 & 0 \\
& $16-20 \mathrm{~m}$ & 0.016 & 0.013 & 0.006 & 0.002 & 0.002 & 0.001 & 0 & 0 & 0 \\
& sup 20 m & 0.011 & 0.009 & 0.004 & 0.001 & 0.002 & 0 & 0 & 0 & 0 \\
\hline \multirow{3}{*}{ Sole } & $0-10 \mathrm{~m}$ & 0 & 0 & 0 & 0 & 0.001 & 0 & 0 & 0 & 0 \\
gill-netters & $10-12 \mathrm{~m}$ & 0 & 0 & 0 & 0.001 & 0.002 & 0.001 & 0 & 0 & 0 \\
& $12-18 \mathrm{~m}$ & 0 & 0 & 0 & 0.002 & 0.004 & 0.002 & 0.001 & 0 & 0 \\
& $18-24 \mathrm{~m}$ & 0 & 0 & 0.001 & 0.005 & 0.008 & 0.004 & 0.001 & 0.001 & 0 \\
\hline \multirow{2}{*}{ Various fish } & $0-10 \mathrm{~m}$ & 0 & 0 & 0 & 0.001 & 0.002 & 0.001 & 0 & 0 & 0 \\
gill-netters & $10-12 \mathrm{~m}$ & 0 & 0 & 0 & 0.001 & 0.002 & 0.001 & 0 & 0 & 0 \\
& $12-18 \mathrm{~m}$ & 0 & 0 & 0 & 0.002 & 0.004 & 0.002 & 0.001 & 0 & 0 \\
& $18-24 \mathrm{~m}$ & 0 & 0 & 0.005 & 0.025 & 0.044 & 0.023 & 0.008 & 0.003 & 0.002 \\
\hline Other fleets & sup $24 \mathrm{~m}$ & 0 & 0.001 & 0.013 & 0.067 & 0.119 & 0.062 & 0.022 & 0.009 & 0.005 \\
\hline & & 0.022 & 0.253 & 0.444 & 0.734 & 0.764 & 0.843 & 0.728 & 0.875 & 0.88
\end{tabular}

Table A.6: The values of fishing mortality on Sole $(s=3): F_{3, a, f}\left(t_{0}\right)$. Source: ICES; Ifremer, SIH, 2008.

\begin{tabular}{|c|c|c|c|c|c|c|c|c|}
\hline Fleets & sub-fleets Age a & 2 & 3 & 4 & 5 & 6 & 7 & $8+$ \\
\hline \multirow{3}{*}{$\begin{array}{c}\text { Nephrops } \\
\text { trawlers }\end{array}$} & 09-12 m & 0.002 & 0.002 & 0.001 & 0.001 & 0.001 & 0.001 & 0.001 \\
\hline & $12-16 \mathrm{~m}$ & 0.009 & 0.011 & 0.009 & 0.008 & 0.008 & 0.008 & 0.008 \\
\hline & $16-20 \mathrm{~m}$ & 0.005 & 0.006 & 0.005 & 0.004 & 0.004 & 0.004 & 0.004 \\
\hline \multirow{4}{*}{$\begin{array}{l}\text { Various fish } \\
\text { trawlers }\end{array}$} & $0-12 \mathrm{~m}$ & 0.014 & 0.017 & 0.013 & 0.01 & 0.007 & 0.007 & 0.007 \\
\hline & $12-16 \mathrm{~m}$ & 0.014 & 0.018 & 0.014 & 0.012 & 0.013 & 0.013 & 0.013 \\
\hline & $16-20 \mathrm{~m}$ & 0.017 & 0.021 & 0.016 & 0.014 & 0.015 & 0.015 & 0.015 \\
\hline & $\sup 20 \mathrm{~m}$ & 0.007 & 0.009 & 0.007 & 0.006 & 0.007 & 0.006 & 0.006 \\
\hline \multirow{4}{*}{$\begin{array}{c}\text { Sole } \\
\text { gill-netters }\end{array}$} & $0-10 \mathrm{~m}$ & 0.002 & 0.005 & 0.008 & 0.008 & 0.01 & 0.009 & 0.011 \\
\hline & $10-12 \mathrm{~m}$ & 0.011 & 0.028 & 0.042 & 0.045 & 0.053 & 0.052 & 0.059 \\
\hline & $12-18 \mathrm{~m}$ & 0.018 & 0.065 & 0.087 & 0.094 & 0.148 & 0.145 & 0.138 \\
\hline & $18-24 \mathrm{~m}$ & 0.015 & 0.054 & 0.072 & 0.078 & 0.123 & 0.121 & 0.115 \\
\hline \multirow{5}{*}{$\begin{array}{l}\text { Various fish } \\
\text { gill-netters }\end{array}$} & $0-10 \mathrm{~m}$ & 0 & 0.001 & 0.002 & 0.002 & 0.002 & 0.002 & 0.002 \\
\hline & $10-12 \mathrm{~m}$ & 0.001 & 0.003 & 0.005 & 0.005 & 0.006 & 0.006 & 0.007 \\
\hline & $12-18 \mathrm{~m}$ & 0.001 & 0.003 & 0.004 & 0.004 & 0.006 & 0.006 & 0.006 \\
\hline & $18-24 \mathrm{~m}$ & 0 & 0 & 0 & 0 & 0 & 0 & 0 \\
\hline & $\sup 24 \mathrm{~m}$ & 0 & 0 & 0 & 0 & 0 & 0 & 0 \\
\hline Other fleets & & 0.062 & 0.113 & 0.072 & 0.072 & 0.09 & 0.079 & 0.083 \\
\hline
\end{tabular}


Table A.7: Biological reference points $B_{s}^{\mathrm{lim}}, B_{s}^{\mathrm{pa}}$ and mean recruitment $\bar{R}_{s}$ for every species. This last one is computed over 1987-2006 for the Nephrops, 1992-2006 for the Hake and 1993-2006 for the Sole. Source: ICES; Ifremer, SIH.

\begin{tabular}{l|ccc} 
& Nephrops & Hake & Sole \\
\hline$B_{s}^{\lim }$ (tons) & 7733 & 54521 & 9706 \\
$B_{s}^{\mathrm{pa}}$ (tons) & 7733 & 75784 & 13000 \\
$\bar{R}_{s}\left(10^{3}\right.$ individuals $)$ & 699387 & 241776 & 23414
\end{tabular}

Table A.8: Estimated discard in percentage for Nephrops $(s=1)$ : $d_{1, a, f}$. Source: ICES; Ifremer, SIH, 2008.

\begin{tabular}{c|lllllllll}
\hline Main fleets & 1 & 2 & 3 & 4 & 5 & 6 & 7 & 8 & 9 \\
\hline Nephrops trawlers & 0.999 & 0.972 & 0.344 & 0.063 & 0.023 & 0.013 & 0.014 & 0.017 & 0.01 \\
Various fish trawlers & 0.999 & 0.972 & 0.344 & 0.063 & 0.023 & 0.013 & 0.014 & 0.017 & 0.01 \\
Sole gill-netters & 0.999 & 0.972 & 0.344 & 0.063 & 0.023 & 0.013 & 0.014 & 0.017 & 0.01 \\
Various fish gill-netters & 0.999 & 0.972 & 0.344 & 0.063 & 0.023 & 0.013 & 0.014 & 0.017 & 0.01
\end{tabular}

Table A.9: Estimated discard in percentage for Hake $(s=2): d_{2, a, f}$. Source: ICES; Ifremer, SIH, 2008.

\begin{tabular}{c|lllllllll}
\hline Main fleets & 0 & 1 & 2 & 3 & 4 & 5 & 6 & 7 & $8+$ \\
\hline Nephrops trawlers & 0.999 & 0.374 & 0. & 0. & 0. & 0. & 0. & 0. & 0. \\
Various fish trawlers & 0.998 & 0.237 & 0. & 0. & 0. & 0. & 0. & 0. & 0. \\
Sole gill-netters & 0. & 0. & 0. & 0. & 0. & 0. & 0. & 0. & 0. \\
Various fish gill-netters & 0. & 0. & 0. & 0. & 0. & 0. & 0. & 0. & 0.
\end{tabular}

Table A.10: Estimated discard in percentage for Sole $(s=3): d_{3, a, f}$. Source: ICES; Ifremer, SIH, 2008.

\begin{tabular}{c|lllllll}
\hline Age a & 2 & 3 & 4 & 5 & 6 & 7 & $8+$ \\
\hline Nephrops trawlers & 0.15 & 0.01 & 0. & 0. & 0. & 0. & 0. \\
Various fish trawlers & 0.15 & 0.01 & 0. & 0. & 0. & 0. & 0. \\
Sole gill-netters & 0.15 & 0.01 & 0. & 0. & 0. & 0. & 0. \\
Various fish gill-netters & 0.15 & 0.01 & 0. & 0. & 0. & 0. & 0.
\end{tabular}


Table A.11: Initial number of vessels $\mathrm{K}_{f}\left(t_{0}\right)$, effort by vessel $e_{f}\left(t_{0}\right)$ and rate of extra fishing income $\alpha_{f}$ of the sixteen sub-fleets. Source: Ifremer, SIH, DPMA, 2008.

\begin{tabular}{|c|c|c|c|c|}
\hline Fleets & length(m) & $\begin{array}{c}\text { nb vessel } \\
\mathrm{K}_{f}\left(t_{0}\right)\end{array}$ & $\begin{array}{c}\text { fishing effort/ vessel } \\
\text { (nb day at sea) } \\
e_{f}\left(t_{0}\right)\end{array}$ & $\begin{array}{c}\text { income from other species } \\
\qquad \begin{array}{c}\text { (in } € / \text { effort unit) } \\
\alpha_{f}\end{array}\end{array}$ \\
\hline \multirow{3}{*}{$\begin{array}{c}\text { Nephrops trawlers } \\
\qquad f=1,2,3\end{array}$} & $09-12 \mathrm{~m}$ & 19 & 170.3 & 297 \\
\hline & $12-16 \mathrm{~m}$ & 75 & 183.4 & 429 \\
\hline & $16-20 \mathrm{~m}$ & 22 & 177. & 716 \\
\hline \multirow{4}{*}{$\begin{array}{c}\text { Various fish } \\
\text { trawlers } f=4,5,6,7\end{array}$} & $0-12 \mathrm{~m}$ & 110 & 157.7 & 622 \\
\hline & $12-16 \mathrm{~m}$ & 45 & 192.7 & 1375 \\
\hline & $16-20 \mathrm{~m}$ & 49 & 180.3 & 1751 \\
\hline & $\sup 20 \mathrm{~m}$ & 37 & 197.1 & 3597 \\
\hline \multirow{4}{*}{$\begin{array}{l}\text { Sole gill-netters } \\
f=8,9,10,11\end{array}$} & $0-10 \mathrm{~m}$ & 28 & 139. & 311 \\
\hline & $10-12 \mathrm{~m}$ & 42 & 145.5 & 503 \\
\hline & $12-18 \mathrm{~m}$ & 40 & 202.9 . & 765 \\
\hline & $18-24 \mathrm{~m}$ & 23 & 201.7 & 1150 \\
\hline \multirow{5}{*}{$\begin{array}{l}\text { Various fish gill-netters } \\
f=12,13,14,15,16\end{array}$} & $0-10 \mathrm{~m}$ & 32 & 153.8 & 303 \\
\hline & $10-12 \mathrm{~m}$ & 30 & 178.8 & 847 \\
\hline & $12-18 \mathrm{~m}$ & 6 & 145. & 1466 \\
\hline & $18-24 \mathrm{~m}$ & 9 & 210.3 & 1500 \\
\hline & $\sup 24 \mathrm{~m}$ & 10 & 260.6 & 1141 \\
\hline
\end{tabular}

Table A.12: Mean reference costs of the sixteen sub-fleets. Source: Ifremer, SIH, DPMA, 2008

\begin{tabular}{|c|c|c|c|c|c|}
\hline Fleets & length(m) & $\begin{array}{c}\text { landing cost } \\
\qquad \tau_{f}\end{array}$ & $\begin{array}{c}\text { volume of fuel } \\
\text { (in } \mathrm{L} / \text { effort unit) } \\
\mathrm{V}_{f}^{\text {fuel }}\end{array}$ & $\begin{array}{c}\text { variable cost } \\
\text { by vessel } \\
\text { (in } € / \text { effort unit) } \\
c_{f}^{v a r}\end{array}$ & $\begin{array}{c}\text { annual costs } \\
\text { by vessel } \\
\text { (in €) } \\
c_{f}^{f i x}\end{array}$ \\
\hline \multirow{3}{*}{$\begin{array}{c}\text { Nephrops trawlers } \\
\qquad f=1,2,3\end{array}$} & 09-12 m & 0.04 & 482 & 58 & 101837 \\
\hline & $12-16 \mathrm{~m}$ & 0.05 & 653 & 81 & 174104 \\
\hline & $16-20 \mathrm{~m}$ & 0.07 & 925 & 160 & 234836 \\
\hline \multirow{4}{*}{$\begin{array}{c}\text { Various fish } \\
\text { trawlers } f=4,5,6,7\end{array}$} & $0-12 \mathrm{~m}$ & 0.05 & 257 & 44 & 77779 \\
\hline & $12-16 \mathrm{~m}$ & 0.05 & 863 & 108 & 218506 \\
\hline & $16-20 \mathrm{~m}$ & 0.07 & 1076 & 188 & 245285 \\
\hline & $\sup 20 \mathrm{~m}$ & 0.07 & 1999 & 308 & 388951 \\
\hline \multirow{4}{*}{$\begin{array}{l}\text { Sole gill-netters } \\
f=8,9,10,11\end{array}$} & $0-10 \mathrm{~m}$ & 0.06 & 78 & 70 & 56601 \\
\hline & $10-12 \mathrm{~m}$ & 0.05 & 290 & 140 & 132326 \\
\hline & $12-18 \mathrm{~m}$ & 0.08 & 348 & 213 & 256373 \\
\hline & $18-24 \mathrm{~m}$ & 0.07 & 622 & 453 & 378872 \\
\hline \multirow{5}{*}{$\begin{array}{l}\text { Various fish gill-netters } \\
f=12,13,14,15,16\end{array}$} & $0-10 \mathrm{~m}$ & 0.05 & 59 & 28 & 42874 \\
\hline & $10-12 \mathrm{~m}$ & 0.05 & 248 & 69 & 111911 \\
\hline & $12-18 \mathrm{~m}$ & 0.06 & 396 & 230 & 223622 \\
\hline & $18-24 \mathrm{~m}$ & 0.07 & 811 & 595 & 513353 \\
\hline & $\sup 24 \mathrm{~m}$ & 0.03 & 1099 & 556 & 913096 \\
\hline
\end{tabular}

